\title{
An improved retrieval of tropospheric nitrogen dioxide from GOME
}

\section{Citation}

Martin, Randall V., Kelly Chance, Daniel J. Jacob, Thomas P. Kurosu, Robert J. D. Spurr, Eric Bucsela, James F. Gleason, Paul I. Palmer, Isabelle Bey, Arlene M. Fiore, Qinbin Li, Robert M. Yantosca, and Robert B. A. Koelemeijer. 2002. "An Improved Retrieval of Tropospheric Nitrogen Dioxide from GOME." Journal of Geophysical Research 107 (D20). doi:10.1029/2001jd001027.

\section{Published Version}

doi:10.1029/2001JD001027

\section{Permanent link}

http://nrs.harvard.edu/urn-3:HUL.InstRepos:14121771

\section{Terms of Use}

This article was downloaded from Harvard University's DASH repository, and is made available under the terms and conditions applicable to Other Posted Material, as set forth at http:// nrs.harvard.edu/urn-3:HUL.InstRepos:dash.current.terms-of-use\#LAA

\section{Share Your Story}

The Harvard community has made this article openly available.

Please share how this access benefits you. Submit a story.

\section{Accessibility}




\title{
An improved retrieval of tropospheric nitrogen dioxide from GOME
}

\author{
Randall V. Martin, ${ }^{1}$ Kelly Chance, ${ }^{2}$ Daniel J. Jacob, ${ }^{1}$ Thomas P. Kurosu, ${ }^{2}$ \\ Robert J. D. Spurr, ${ }^{2}$ Eric Bucsela, ${ }^{3}$ James F. Gleason, ${ }^{3}$ Paul I. Palmer, ${ }^{1}$ Isabelle Bey, ${ }^{1,4}$ \\ Arlene M. Fiore, ${ }^{1}$ Qinbin Li, ${ }^{1}$ Robert M. Yantosca, ${ }^{1}$ and Robert B. A. Koelemeijer ${ }^{5}$ \\ Received 5 July 2001; revised 4 December 2001; accepted 12 March 2002; published 25 October 2002.
}

[1] We present a retrieval of tropospheric nitrogen dioxide $\left(\mathrm{NO}_{2}\right)$ columns from the Global Ozone Monitoring Experiment (GOME) satellite instrument that improves in several ways over previous retrievals, especially in the accounting of Rayleigh and cloud scattering. Slant columns, which are directly fitted without low-pass filtering or spectral smoothing, are corrected for an artificial offset likely induced by spectral structure on the diffuser plate of the GOME instrument. The stratospheric column is determined from $\mathrm{NO}_{2}$ columns over the remote Pacific Ocean to minimize contamination from tropospheric $\mathrm{NO}_{2}$. The air mass factor (AMF) used to convert slant columns to vertical columns is calculated from the integral of the relative vertical $\mathrm{NO}_{2}$ distribution from a global 3-D model of tropospheric chemistry driven by assimilated meteorological data (Global Earth Observing System (GEOS)-CHEM), weighted by altitude-dependent scattering weights computed with a radiative transfer model (Linearized Discrete Ordinate Radiative Transfer), using local surface albedos determined from GOME observations at $\mathrm{NO}_{2}$ wavelengths. The AMF calculation accounts for cloud scattering using cloud fraction, cloud top pressure, and cloud optical thickness from a cloud retrieval algorithm (GOME Cloud Retrieval Algorithm). Over continental regions with high surface emissions, clouds decrease the AMF by 20 $30 \%$ relative to clear sky. GOME is almost twice as sensitive to tropospheric $\mathrm{NO}_{2}$ columns over ocean than over land. Comparison of the retrieved tropospheric $\mathrm{NO}_{2}$ columns for July 1996 with GEOS-CHEM values tests both the retrieval and the nitrogen oxide radical $\left(\mathrm{NO}_{\mathrm{x}}\right)$ emissions inventories used in GEOS-CHEM. Retrieved tropospheric $\mathrm{NO}_{2}$ columns over the United States, where $\mathrm{NO}_{\mathrm{x}}$ emissions are particularly well known, are within $18 \%$ of GEOS-CHEM columns and are strongly spatially correlated $(\mathbf{r}=0.78, \mathrm{n}=288, \mathrm{p}<$ 0.005). Retrieved columns show more $\mathrm{NO}_{2}$ than GEOS-CHEM columns over the Transvaal region of South Africa and industrial regions of the northeast United States and Europe. They are lower over Houston, India, eastern Asia, and the biomass burning region of central Africa, possibly because of biases from absorbing aerosols. INDEX TERMS: 0394 Atmospheric Composition and Structure: Instruments and techniques; 0365 Atmospheric Composition and Structure: Troposphere-composition and chemistry; 0345 Atmospheric Composition and Structure:

Pollution — urban and regional (0305)

Citation: Martin, R. V., et al., An improved retrieval of tropospheric nitrogen dioxide from GOME, J. Geophys. Res., 107(D20), 4437, doi:10.1029/2001JD001027, 2002.

\section{Introduction}

[2] Nitrogen oxide radicals $\left(\mathrm{NO}_{\mathrm{x}} \equiv \mathrm{NO}+\mathrm{NO}_{2}\right)$ originating from combustion, lightning, and soils largely control

\footnotetext{
${ }^{1}$ Division of Engineering and Applied Sciences and Department of Earth and Planetary Sciences, Harvard University, Cambridge, Massachusetts, USA.

${ }^{2}$ Harvard-Smithsonian Center for Astrophysics, Cambridge, Massachusetts, USA.

${ }^{3}$ NASA Goddard Space Flight Center, Greenbelt, Maryland, USA.

${ }^{4}$ Now at Ecole Polytechnique Federale de Lausanne, Lausanne, Switzerland.

${ }^{5}$ Space Research Organization Netherlands, Utrecht, Netherlands.

Copyright 2002 by the American Geophysical Union. 0148-0227/02/2001JD001027\$09.00
}

tropospheric ozone production [Kasibhatla et al., 1991; Penner et al., 1991; Murphy et al., 1993; Jacob et al., 1996]. Considerable uncertainty exists in the magnitude and distribution of $\mathrm{NO}_{\mathrm{x}}$ emissions [Emmons et al., 1997; Lee et al., 1997]. Global mapping of nitrogen dioxide $\left(\mathrm{NO}_{2}\right)$ atmospheric concentrations from space could provide critical information for constraining $\mathrm{NO}_{\mathrm{x}}$ emissions and more generally improve our understanding of tropospheric chemistry [National Research Council, 2001].

[3] The Global Ozone Monitoring Experiment (GOME) instrument [Burrows et al., 1993, 1999a; ESA, 1995] on board the European Remote Sensing-2 satellite provides the capability for continuous global monitoring of $\mathrm{NO}_{2}$ atmospheric columns through observation of solar backscatter at $0.31 \mathrm{~nm}$ spectral resolution between 423 and $451 \mathrm{~nm}$ where 
$\mathrm{NO}_{2}$ has strong absorption features. The satellite was launched in April 1995 into a $98.5^{\circ}$ inclination Sun-synchronous orbit, crossing the equator at $1030 \mathrm{AM}$ local time in the descending node. The GOME instrument observes the atmosphere in the nadir view with a surface spatial resolution of $40 \mathrm{~km}$ latitude by $320 \mathrm{~km}$ longitude in the forward scan, using a scanning mirror to measure 3 such scenes across the flight track. Global coverage is achieved every 3 days after 43 orbits. The instrument has broadband polarization monitoring devices (PMDs) with surface spatial resolution of 20 by $40 \mathrm{~km}^{2}$ that are useful in determining cloud fraction [Kurosu et al., 1999].

[4] Leue et al. [2001] and Velders et al. [2001] have previously demonstrated the usefulness of $\mathrm{NO}_{2}$ measurements from GOME for mapping surface emissions of $\mathrm{NO}_{\mathrm{x}}$. Over $\mathrm{NO}_{\mathrm{x}}$ source regions the tropospheric component of the $\mathrm{NO}_{2}$ column is comparable in magnitude to the stratospheric component that originates from $\mathrm{N}_{2} \mathrm{O}$ oxidation in the middle stratosphere. The tropospheric $\mathrm{NO}_{2}$ column tracks surface $\mathrm{NO}_{\mathrm{x}}$ emissions on a regional scale since $\mathrm{NO}_{2}$ typically accounts for $\sim 80 \%$ of $\mathrm{NO}_{\mathrm{x}}$ in the boundary layer and the lifetime of $\mathrm{NO}_{\mathrm{x}}$ against oxidation in the boundary layer is on the order of a day.

[5] Four major challenges are involved in quantifying tropospheric $\mathrm{NO}_{2}$ columns from GOME. The first is to determine the total $\mathrm{NO}_{2}$ slant column from the radiance and solar irradiance measurements. The second is to remove a daily varying artificial offset in the $\mathrm{NO}_{2}$ slant columns thought to be introduced by the diffuser plate of the GOME instrument. The third is to remove the stratospheric column to obtain the tropospheric residual. The fourth challenge is to convert the tropospheric slant columns to vertical columns with a proper air mass factor (AMF) that accounts for atmospheric scattering, including the effect of clouds [Koelemeijer and Stammes, 1999; Velders et al., 2001; Richter and Burrows, 2002].

[6] Previous retrievals of tropospheric $\mathrm{NO}_{2}$ [Leue et al., 2001; Velders et al., 2001; Richter and Burrows, 2002] employed differential optical absorption spectroscopy [e.g., Platt, 1994] to determine the $\mathrm{NO}_{2}$ slant column. Only Richter and Burrows [2002] addressed the diffuser plate artifact by fitting all GOME observations with a single solar spectrum. The separation of tropospheric and stratospheric columns differed slightly among the three studies. Both Leue et al. [2001] and Velders et al. [2001] used GOME observations of cloudy scenes over marine regions at least $200 \mathrm{~km}$ from shore to determine a stratospheric background and infer the global stratospheric distribution using a twodimensional interpolation algorithm. Richter and Burrows [2002] determined the stratospheric background from GOME observations between $180^{\circ} \mathrm{W}$ and $170^{\circ} \mathrm{W}$ and inferred the global stratospheric background assuming zonal invariance. In the radiative transfer calculation used to derive the AMF, all three studies assumed the tropospheric $\mathrm{NO}_{2}$ column to be confined below about $1.5 \mathrm{~km}$ and evenly distributed there. Leue et al. [2001] employed land albedos of about $10-20 \%$ and ocean albedos of about $5-10 \%$ while Velders et al. [2001] and Richter and Burrows [2002] assumed surface albedos of 5\%. Both Leve et al. [2001] and Velders et al. [2001] multiplied their tropospheric columns by a correction factor of about 4 over nondesert regions, assuming that clouds obscure the $\mathrm{NO}_{2}$ column.
Velders et al. [2001] estimated an uncertainty of 50\% from their assumption of a fixed $\mathrm{NO}_{2}$ profile in the AMF calculation and an uncertainty of $100 \%$ from their cloud correction. Richter and Burrows [2002] examined the differences between scenes with cloud fractions less than 0.1 and greater than 0.3 to infer the amount of $\mathrm{NO}_{2}$ in the free troposphere.

[7] The present work improves on these retrievals in several aspects. Radiance spectra are directly fitted without high-pass filtering or spectral smoothing following the works of Chance [1998] and Chance et al. [2000]. The fit is performed using $\mathrm{NO}_{2}$ absorption spectra at $293 \mathrm{~K}$, appropriate for boundary layer $\mathrm{NO}_{2}$. Correction for spectral undersampling by the GOME instrument, wavelength calibration with a Fraunhofer reference spectrum [Chance and Spurr, 1997], treatment of the Ring effect, and inclusion of a common mode spectrum follow the works of Chance [1998] and Chance et al. [2000]. We determine the stratospheric column and the diffuser plate artifact from GOME over Pacific regions with minimal tropospheric $\mathrm{NO}_{2}$, correct the latitudinally varying bias introduced by this approach, and estimate the error from the assumption of zonal invariance using limb observations of stratospheric $\mathrm{NO}_{2}$ from the Halogen Occultation Experiment (HALOE) instrument [Russell et al., 1993]. Our AMF calculation combines a radiative transfer model with local surface albedos determined from GOME and vertical shape factors of $\mathrm{NO}_{2}$ locally determined from a global 3-D model of tropospheric chemistry, following the formulation of Palmer et al. [2001]. We extend that formulation to account for scattering by clouds using local cloud fraction, cloud top pressure, and cloud optical thickness information from the GOME Cloud Retrieval Algorithm (GOMECAT) [Kurosu et al., 1999]. In the GOMECAT algorithm, cloud fraction is determined from the PMDs while cloud top pressure and cloud optical thickness are obtained from GOME radiances in and around the $\mathrm{O}_{2} A$ band.

[8] We provide below a description of the method and apply it to a retrieval study for July 1996. Section 2 describes the atmospheric chemistry model used in the retrieval. In section 3 we present the AMF formulation to account for scattering by clouds. The fitting of total slant columns is described in section 4 . We remove the nontropospheric column in section 5. Tropospheric slant and vertical columns are presented in section 6 . Section 7 discusses the errors in the retrieval.

\section{Atmospheric Chemistry Model Used in the Retrieval}

[9] Retrieving tropospheric $\mathrm{NO}_{2}$ columns from GOME requires some assumptions regarding the vertical distribution of $\mathrm{NO}_{2}$. A global 3-D model of tropospheric chemistry is the best source for this information considering the sparseness of $\mathrm{NO}_{2}$ in situ observations and the large spatial variability of $\mathrm{NO}_{2}$ profiles. We use the Global Earth Observing System (GEOS)-CHEM model [Bey et al., 2001a] driven by assimilated meteorological observations for 1996, updated every 3-6 hours, from the GEOS of the NASA Data Assimilation Office (DAO) [Schubert et al., 1993]. The model version used here has 26 vertical levels on a sigma coordinate (surface to $0.1 \mathrm{hPa}$ ), and a horizontal 
Table 1. Annual Global $\mathrm{NO}_{\mathrm{x}}$ Emissions in the GEOS-CHEM Model

\begin{tabular}{lc}
\hline \multicolumn{1}{c}{ Source } & $\begin{array}{c}\text { Emission Rate, } \\
\mathrm{Tg} \mathrm{N} \mathrm{yr}^{-1}\end{array}$ \\
\hline Fossil fuel combustion & 23.1 \\
Soils & 5.2 \\
Biomass burning & 5.1 \\
Lightning & 2.9 \\
Biofuels & 2.2 \\
Aircraft & 0.5 \\
Stratosphere & $0.2^{\mathrm{a}}$ \\
\hline \multicolumn{1}{c}{${ }^{\mathrm{a}}$ The cross-tropopause $\mathrm{NO}_{\mathrm{y}}$ flux is $0.7 \mathrm{Tg} \mathrm{N} \mathrm{yr}^{-1}$ (including $0.2 \mathrm{Tg} \mathrm{N}$} \\
$\mathrm{yr}^{-1}$ as $\mathrm{NO}_{\mathrm{x}}$ and $0.5 \mathrm{Tg} \mathrm{N} \mathrm{yr}^{-1}$ as $\mathrm{HNO}_{3}$ ).
\end{tabular}

resolution of $2^{\circ}$ latitude by $2.5^{\circ}$ longitude. It includes a detailed description of tropospheric ozone $-\mathrm{NO}_{\mathrm{x}}$ - hydrocarbon chemistry. It solves the chemical evolution of about 120 species with a Gear solver [Jacobson and Turco, 1994] and transports 24 tracers. Photolysis rates are computed using the Fast-J radiative transfer algorithm [Wild et al., 2000] which includes Rayleigh scattering as well as Mie scattering by aerosols and clouds. The annual mean tropopause is diagnosed locally in the model using the standard criterion of a $2 \mathrm{~K} \mathrm{~km}^{-1}$ lapse rate. This model version (based on GEOS-CHEM 4.11, http://www-as.harvard.edu/chemistry/ trop/geos) includes several updates relative to the original Bey et al. [2001a] version, as described by Martin et al. [2002]. The most important for the present application are monthly averaged UV surface reflectivity fields [Herman et al., 1997], Mie scattering by mineral dust, heterogeneous chemistry on mineral dust aerosols, improved biomass burning and biofuel emission inventories, and improved seasonal variation in biomass burning emissions as summarized below.

[10] Table 1 contains the annual global $\mathrm{NO}_{\mathrm{x}}$ emissions used in the model. Anthropogenic $\mathrm{NO}_{\mathrm{x}}$ emissions are from the Global Emission Inventory Activity (GEIA) [Benkovitz et al., 1996] partitioned among individual countries and scaled to 1996 levels as described by Bey et al. [2001a]. Emissions of $\mathrm{NO}_{\mathrm{x}}$ from lightning are linked to deep convection following the parameterization of Price and Rind [1992] as implemented by Wang et al. [1998] with vertical profiles from the work of Pickering et al. [1998]. Soil $\mathrm{NO}_{\mathrm{x}}$ emissions are computed locally using a modified version of the Yienger and Levy [1995] algorithm, as described by Wang et al. [1998] and Bey et al. [2001a]. New emission inventories are used for biofuels and biomass burning (J. Logan and R. Yevich, personal communication, 2001). We use vegetation specific emission factors as described by Staudt et al. (Sources and chemistry of nitrogen oxides over the tropical Pacific, submitted to Journal of Geophysical Research, 2002). Seasonal variation in biomass burning emissions is determined from satellite observations [Duncan et al., 2002]. Ship emissions of $\mathrm{NO}_{\mathrm{x}}$ are from GEIA (0.2 $\left.\mathrm{Tg} \mathrm{N} \mathrm{yr}^{-1}\right)$. Corbett et al. [1999] have proposed that ship emissions may be much higher $\left(3.0 \mathrm{Tg} \mathrm{N} \mathrm{yr}^{-1}\right)$, but this would result in a large model overestimate of $\mathrm{NO}_{\mathrm{x}}$ over the North Atlantic [Kasibhatla et al., 2000; Davis et al., 2001].

[11] Of particular interest here is the ability of the model to provide a realistic simulation of the tropospheric $\mathrm{NO}_{2}$ relative vertical distribution (shape factor) for the AMF calculation. Few in situ observations of $\mathrm{NO}_{2}$ exist, but a large body of aircraft observations for $\mathrm{NO}$ is available [Emmons et al., 1997; Thakur et al., 1999]. Considering that the $\mathrm{NO}_{2} / \mathrm{NO}$ ratio from photochemical steady state in the model is known to match observations closely [Bradshaw et al., 1999], observed vertical profiles of NO provide a good surrogate for $\mathrm{NO}_{2}$ evaluation. Detailed evaluations of the GEOS-CHEM NO fields with observations are presented in several papers [Bey et al., 2001a, 2001b; Fiore et al., 2002; Martin et al., 2002]. They show that the model generally captures the spatial and temporal variability in NO profiles, reproducing observed NO concentrations within a factor of 2. The largest relative discrepancies are over the Pacific where the model is up to a factor of 2 too high [Bey et al., 2001a].

[12] Figure 1 shows four representative profiles over a range of conditions: (top left) clean troposphere, (top right) remote troposphere affected by biomass burning outflow, (bottom left) ocean region downwind of a major source region, and (bottom right) source region during summer. The corresponding $\mathrm{NO}_{2}$ mixing ratio profiles would be skewed toward the lower troposphere since the daytime $\mathrm{NO}_{2} / \mathrm{NO}$ ratio typically decreases by a factor of 25 from the surface to the upper troposphere [Bradshaw et al., 1999], largely due to the temperature dependence of the $\mathrm{NO}+\mathrm{O}_{3}$ reaction. As shown in Figure 1, the $\mathrm{NO}_{2}$ number density profiles are skewed further toward the lower troposphere. As a result, GOME is relatively insensitive to upper tropospheric $\mathrm{NO}_{\mathrm{x}}$ enhancements from aircraft and lightning.

[13] The shape of the vertical profile shows large variability depending on the region, and the model largely captures this variability, as shown in Figure 1. The model underestimates the high upper tropospheric NO concentrations over the tropical South Atlantic from biomass burning and lightning [Jacob et al., 1996; Pickering et al., 1996] by up to $50 \%$. Over the Pacific, the model overestimates lower tropospheric NO concentrations by up to $50 \%$. Over the North Atlantic, the model reproduces well the observed vertical profile and high spatial variability. Over Tennessee the model simulates the observed boundary layer enhancement but underestimates its magnitude. The profile shape over source regions is largely determined by the local boundary layer depth. The model simulation of boundary layer depths will be discussed in section 7 .

\section{AMF Calculation}

[14] The AMF is defined here as the ratio of the fitted ("slant") to the vertical tropospheric column of $\mathrm{NO}_{2}$. The stratospheric component of the slant column is subtracted prior to the application of the AMF as described in section 5. The AMF is sensitive to the relative vertical distribution of $\mathrm{NO}_{2}$ due to Rayleigh scattering and to Mie scattering by clouds. Backscattered radiances measured by GOME can be strongly influenced by clouds, even if clouds constitute only a small fraction of a GOME scene [Koelemeijer and Stammes, 1999; Velders et al., 2001; Richter and Burrows, 2002]. An important feature of our AMF formulation is that it enables quantitative retrieval for partly cloudy scenes, which represent the general case for GOME because of the 

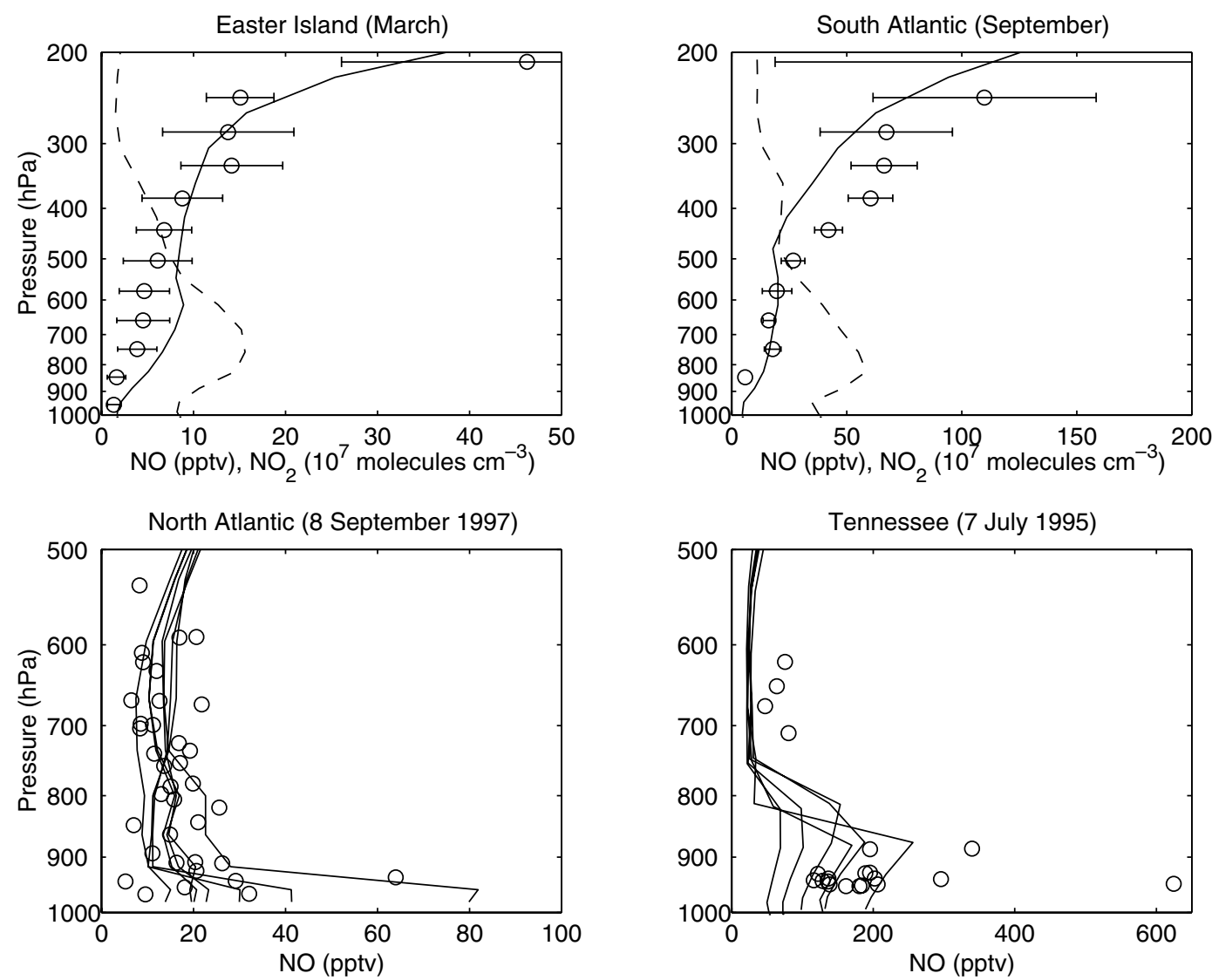

Figure 1. Comparison of NO concentrations between the GEOS-CHEM model (solid lines) and aircraft observations (circles) over Easter Island in March 1999 [Raper et al., 2002], the tropical South Atlantic in September 1992 [Fishman et al., 1996b], the North Atlantic off the east coast of Nova Scotia on 8 September 1997 [Ryerson et al., 1999], and Tennessee on 7 July 1995 [Hübler et al., 1998]. For Easter Island and the tropical South Atlantic, the observations are means and standard deviations from several flights in the region [Bey et al., 2001a]. Model results are monthly means for 1997 (top left) and 1996 (top right), i.e., not the same years as the observations. For the North Atlantic and Tennessee, the model results are for the specific day of the flight and the different lines represent the ensemble of grid squares sampled by the flight tracks [Fiore et al., 2002]. The dashed lines in the top panels show the modeled $\mathrm{NO}_{2}$ number density profiles.

large scene size $\left(40 \times 320 \mathrm{~km}^{2}\right)$. The method is described here for $\mathrm{NO}_{2}$ and for a single cloud layer in each scene, but can be applied to any optically thin absorber and to multiple cloud or aerosol layers. A scattering aerosol layer in an otherwise clear sky would be diagnosed as a cloud of small optical thickness in the GOMECAT algorithm.

\subsection{General AMF Formulation}

[15] We apply the general AMF formulation of Palmer et al. [2001] to tropospheric $\mathrm{NO}_{2}$ from GOME. This formulation decouples the vertical dependence of the GOME sensitivity to the atmospheric species of interest (calculated with a radiative transfer model) from the shape of the vertical profile of concentrations (calculated with an atmospheric chemistry model). Dimensionless shape factors $S(\sigma)$ over the sigma $(\sigma)$ vertical coordinate are determined from the GEOS-CHEM model for each individual observation scene

$$
S(\sigma)=C(\sigma) \frac{\Omega_{\text {air }}}{\Omega}
$$

where $\Omega_{\text {air }}$ and $\Omega$ are the tropospheric vertical columns of air and $\mathrm{NO}_{2}$, and $C(\sigma)$ is the $\mathrm{NO}_{2}$ mixing ratio. Pressure $P$ is related to $\sigma$ by $P=\sigma\left(P_{s}-P_{u}\right)+P_{u}$, where $P_{u}$ and $P_{s}$ respectively represent the pressures at the model upper boundary and at the surface. Scattering weights $w(\sigma)$ describe the sensitivity of the backscattered radiance $I$ observed by GOME to the abundance of $\mathrm{NO}_{2}$ at each $\sigma$ level

$$
w(\sigma)=-\frac{1}{\mathrm{AMF}_{\mathrm{G}}} \frac{\alpha(\sigma)}{\alpha_{e}} \frac{\partial(\ln I)}{\partial \tau}
$$

where $\alpha(\sigma)$ is the temperature-dependent absorption cross section $\left(\mathrm{m}^{2}\right.$ molecules $\left.{ }^{-1}\right), \alpha_{e}$ is the effective absorption cross section $\left(\mathrm{m}^{2}\right.$ molecules $\left.{ }^{-1}\right)$ representing a weighted average over the tropospheric column [Palmer et al., 2001], and $\partial \tau$ is the incremental $\mathrm{NO}_{2}$ optical depth as a function of $\sigma$. The geometric air mass factor $\mathrm{AMF}_{\mathrm{G}}$, determined simply from the geometric path correction, normalizes the scattering weight such that $w(\sigma)=1$ in a nonscattering 
atmosphere. It is a function of the solar zenith angle $\theta_{o}$ and satellite viewing angle $\theta$

$$
\mathrm{AMF}_{\mathrm{G}}=\sec \theta_{\mathrm{o}}+\sec \theta
$$

The AMF is then given by [Palmer et al., 2001]

$$
\mathrm{AMF}=\mathrm{AMF}_{\mathrm{G}} \int_{\sigma_{T}}^{1} w(\sigma) S(\sigma) d \sigma
$$

where the integral is taken here from the model tropopause $\sigma_{T}$ to the surface. In the absence of scattering, the AMF reduces to $\mathrm{AMF}_{\mathrm{G}}$.

\subsection{Treatment of Partly Cloudy Scenes}

[16] Although the AMF formulation described in equations (1)-(4) is applicable to any scattering atmosphere, Palmer et al. [2001] calculated the scattering weights, $w(\sigma)$, solely for a clear-sky Rayleigh scattering atmosphere. We extend here the AMF formulation to partly cloudy scenes, as typically observed by GOME. The GOMECAT algorithm provides cloud fraction, cloud top pressure, and cloud optical thickness for each scene. The measurement of cloud optical thickness eliminates the need to include a "ghost column" (an assumed value for the column below the cloud) used in other retrievals [i.e., McPeters et al., 1998]. Instead we use a radiative transfer model that includes Mie scattering by clouds to calculate scattering weights for both the clear-sky $\left(w_{a}\right)$ and cloudy $\left(w_{c}\right)$ fractions of the scene at all levels in the troposphere:

$$
\begin{aligned}
& w_{a}(\sigma)=-\frac{1}{\mathrm{AMF}_{\mathrm{G}}} \frac{\alpha(\sigma)}{\alpha_{e}} \frac{\partial\left(\ln I_{a}\right)}{\partial \tau} \\
& w_{c}(\sigma)=-\frac{1}{\mathrm{AMF}_{\mathrm{G}}} \frac{\alpha(\sigma)}{\alpha_{e}} \frac{\partial\left(\ln I_{c}\right)}{\partial \tau}
\end{aligned}
$$

We have decomposed the backscattered radiance $I\left(\mathrm{~W} \mathrm{~m}^{-2}\right.$ $\mathrm{nm}^{-1} \mathrm{sr}^{-1}$ ) observed by GOME for the entire scene into the contributions from the clear-sky $\left(I_{a}\right)$ and cloudy fractions $\left(I_{c}\right)$

$$
I=I_{a}(1-f)+I_{c} f
$$

where $f$ is the cloud fraction $(0 \leq f \leq 1)$. In this manner, AMFs can be calculated for the clear-sky and cloudy fractions of the scene (assuming the same shape factor for each fraction)

$$
\begin{aligned}
& \operatorname{AMF}_{a}=\mathrm{AMF}_{\mathrm{G}} \int_{\sigma_{T}}^{1} w_{a}(\sigma) S(\sigma) d \sigma \\
& \mathrm{AMF}_{c}=\mathrm{AMF}_{\mathrm{G}} \int_{\sigma_{T}}^{1} w_{c}(\sigma) S(\sigma) d \sigma
\end{aligned}
$$

[17] The ratio $I_{a} / I_{c}$ can be expressed in terms of the reflectivity of each subscene $R_{a}$ and $R_{c}$

$$
\frac{I_{a}}{I_{c}}=\frac{R_{a}}{R_{c}}
$$

where the reflectivity is defined as

$$
R_{a}=\frac{\pi I_{a}}{E_{o} \cos \theta_{o}}
$$

$$
R_{c}=\frac{\pi I_{c}}{E_{o} \cos \theta_{o}}
$$

and $E_{o}$ is the solar irradiance at the top of the atmosphere perpendicular to the direction of incident sunlight. The reflectivity of each subscene includes contributions from surface albedo, Rayleigh scattering, and also cloud scattering for the cloudy subscene. Values of $R_{a}$ and $R_{c}$ can be obtained from a radiative transfer model as described below. Substitution of equations (6) and (8) into equation (2) shows that the actual scattering weights $w(\sigma)$ for the partly cloudy scene are the averages of $w_{a}(\sigma)$ and $w_{c}(\sigma)$ weighted by the contribution of each subscene to the backscattered radiance observed by the satellite

$$
w(\sigma)=\frac{w_{a}(\sigma) R_{a}(1-f)+w_{c}(\sigma) R_{c} f}{R_{a}(1-f)+R_{c} f}
$$

Substituting equation (10) into equation (4) yields a similar relationship for the $\mathrm{AMF}$

$$
\mathrm{AMF}=\frac{\mathrm{AMF}_{a} R_{a}(1-f)+\mathrm{AMF}_{c} R_{c} f}{R_{a}(1-f)+R_{c} f}
$$

\subsection{Application to Retrievals of $\mathrm{NO}_{2}$ From GOME}

[18] We calculate scattering weights $\left(w_{a}, w_{c}\right)$ and subscene reflectivities $\left(R_{a}, R_{c}\right)$ using the Linearized Discrete Ordinate Radiative Transfer (LIDORT) model [Spurr et al., 2001]. The LIDORT model solves the radiative transfer equation in a multilayer atmosphere with multiple scattering using the discrete ordinate method [Chandrasekhar, 1960]. We calculate the scattering weights on an altitude coordinate with $0.5 \mathrm{~km}$ vertical resolution below $18 \mathrm{~km}$ and coarser resolution from $18 \mathrm{~km}$ to the top of the atmosphere $(65 \mathrm{~km})$. We then map the results onto the GEOS-CHEM $\sigma$-coordinate. Rayleigh scattering cross sections are calculated as in the work of Chance and Spurr [1997]. Vertical profiles of temperature, pressure, and ozone used in LIDORT are from a midlatitude summer US Standard Atmosphere [1976]. Using profiles from tropical or winter atmospheres affects the AMFs by less than $0.2 \%$.

[19] The surface albedo is treated as Lambertian. We use a surface albedo database derived from GOME measurements at $440 \mathrm{~nm}$ [Koelemeijer et al., 2002], generated as follows. Effective scene albedo was determined for each GOME measurement for the month of July for the years 1995-2000, using the Doubling-Adding KNMI radiative transfer code [De Haan et al., 1987; Stammes, 2000]. The effective scene albedo is the calculated Lambertian surface albedo required to match the observed reflectivity at the top of the atmosphere, assuming a Rayleigh scattering atmosphere. The effective scene albedos were binned by month 

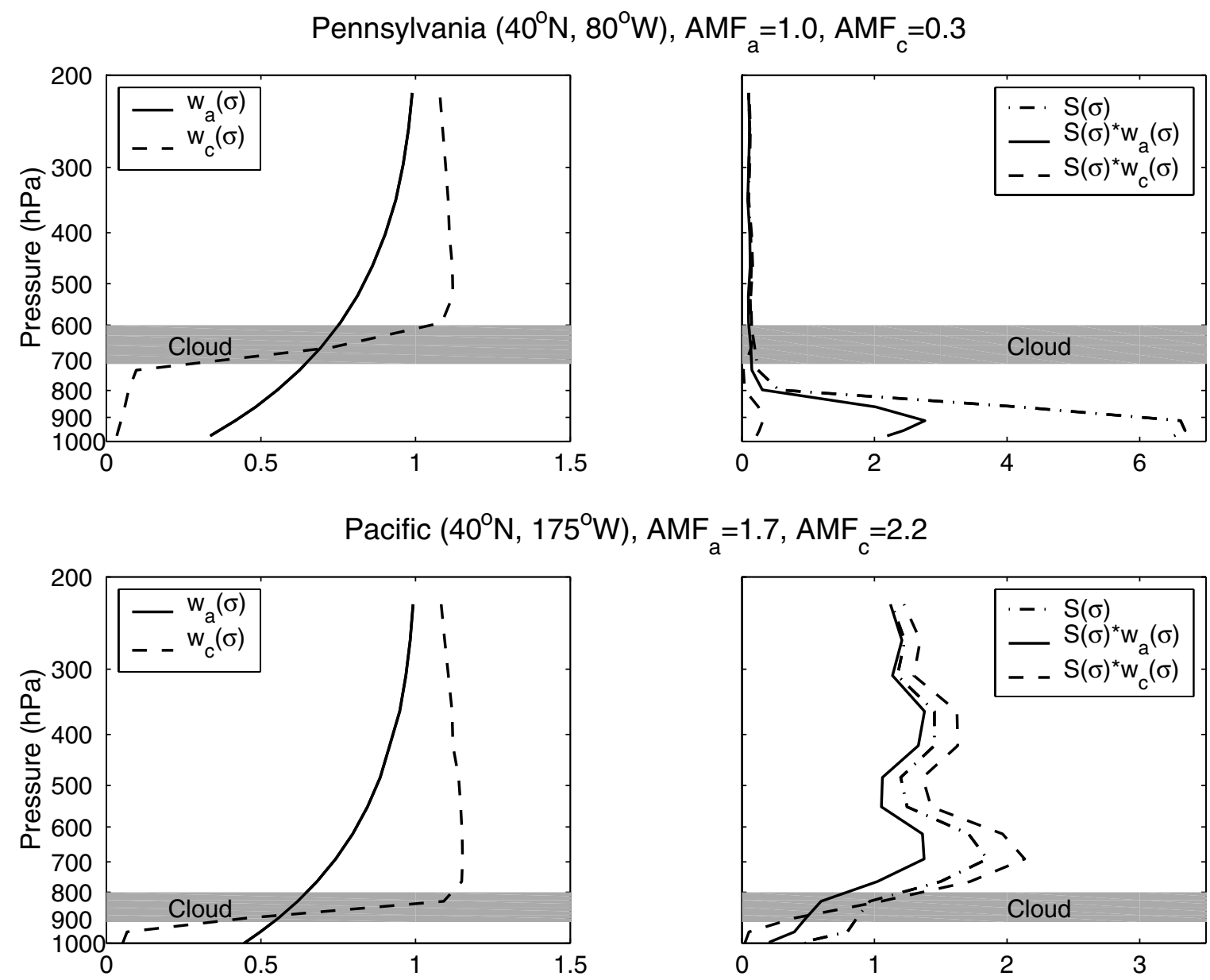

Figure 2. Derivation of the AMFs for sample GOME viewing scenes over western Pennsylvania $\left(40^{\circ} \mathrm{N}\right.$, $\left.80^{\circ} \mathrm{W}\right)$ and the central North Pacific $\left(40^{\circ} \mathrm{N}, 175^{\circ} \mathrm{W}\right)$. The left panels show scattering weights for the clear-sky $w_{a}$ and cloudy $w_{c}$ fractions of the scenes as determined with the LIDORT radiative transfer model. The cloud optical thickness assumed for the cloudy fractions is 10 in both scenes. The cloud top pressure is $800 \mathrm{hPa}$ for the Pacific scene and $600 \mathrm{hPa}$ for the Pennsylvania scene. The right panels show the shape factors $S(\sigma)$ from the GEOS-CHEM model and the products of the shape factor and scattering weight whose integration by equation (7) yields the AMFs. In both scenes, $\mathrm{AMF}_{\mathrm{G}}=2.1$.

and in grid-cells of $1^{\circ}$ by $1^{\circ}$. The surface albedo was then determined as the minimum effective scene albedo in each grid-cell and each month. Effects of persistent clouds over ocean were reduced by replacing the values in such gridcells with a weighted average of adjacent grid-cells.

[20] The surface albedo is generally between $2 \%$ and $10 \%$, except over deserts, snow and ice, and regions of persistent clouds that bias the measurement of surface albedo. Cloud top pressure and cloud optical thickness are obtained from GOMECAT. We estimate cloud base by assuming a cloud optical thickness increment of 8 for each $100 \mathrm{hPa}$ of cloud [Hansen et al., 1983]. The cloud droplet scattering phase function is based on Mie calculations as provided in Fast-J [Wild et al., 2000] for a gamma distribution of cloud droplet sizes with mode radius of 8 $\mu \mathrm{m}$. The single scattering albedo of cloud droplets is assumed to be 1 .

[21] Both $R_{a}$ and $w_{a}$ are dependent on wavelength $\lambda$, surface pressure $P_{s}$, surface albedo $A$, solar zenith angle $\theta_{o}$, and viewing zenith angle $\theta$. Additionally $w_{c}$ and $R_{c}$ are dependent on cloud fraction $f$, cloud optical thickness $\tau_{c}$, and cloud top pressure $P_{c}$. We tabulate these dependencies in the center of the $\mathrm{NO}_{2}$ fitting window $(437 \mathrm{~nm})$ for different $\theta_{o}\left(5^{\circ}, 15^{\circ}, 25^{\circ}, 35^{\circ}, 45^{\circ}, 55^{\circ}, 65^{\circ}, 75^{\circ}, 85^{\circ}\right), \theta$ $\left(0^{\circ}, 23^{\circ}\right), A(0,0.05,0.10,0.15,0.20,0.80,0.90), P_{s}$ $(1000,900,800,600 \mathrm{hPa}), P_{c}(900,800,600,400,200$ $\mathrm{hPa})$, and $\tau_{c}(0,1,2,5,10,20,50,100)$. Calculations are averaged over azimuth angle. Wavelength and azimuth angle dependences are negligible over the range of the fitting window $(423-451 \mathrm{~nm})$ and GOME viewing angles $\left(0^{\circ}-23^{\circ}\right)$.

[22] Figure 2 shows $w_{a}(\sigma), w_{c}(\sigma), S(\sigma)$, and their products for sample scenes in the nadir view $\left(\theta=0^{\circ}\right)$ over the central North Pacific and western Pennsylvania. We see that $w_{a}(\sigma)$ is slightly lower over land than over ocean because of the lower surface albedo of vegetated land surfaces around $440 \mathrm{~nm}$. The scattering weights can be regarded as sensitivities relative to a nonscattering atmosphere. For example, Figure 2 for the clear-sky scene over the Pacific shows that GOME has a sensitivity of roughly $45 \%$ to the mixing ratio 

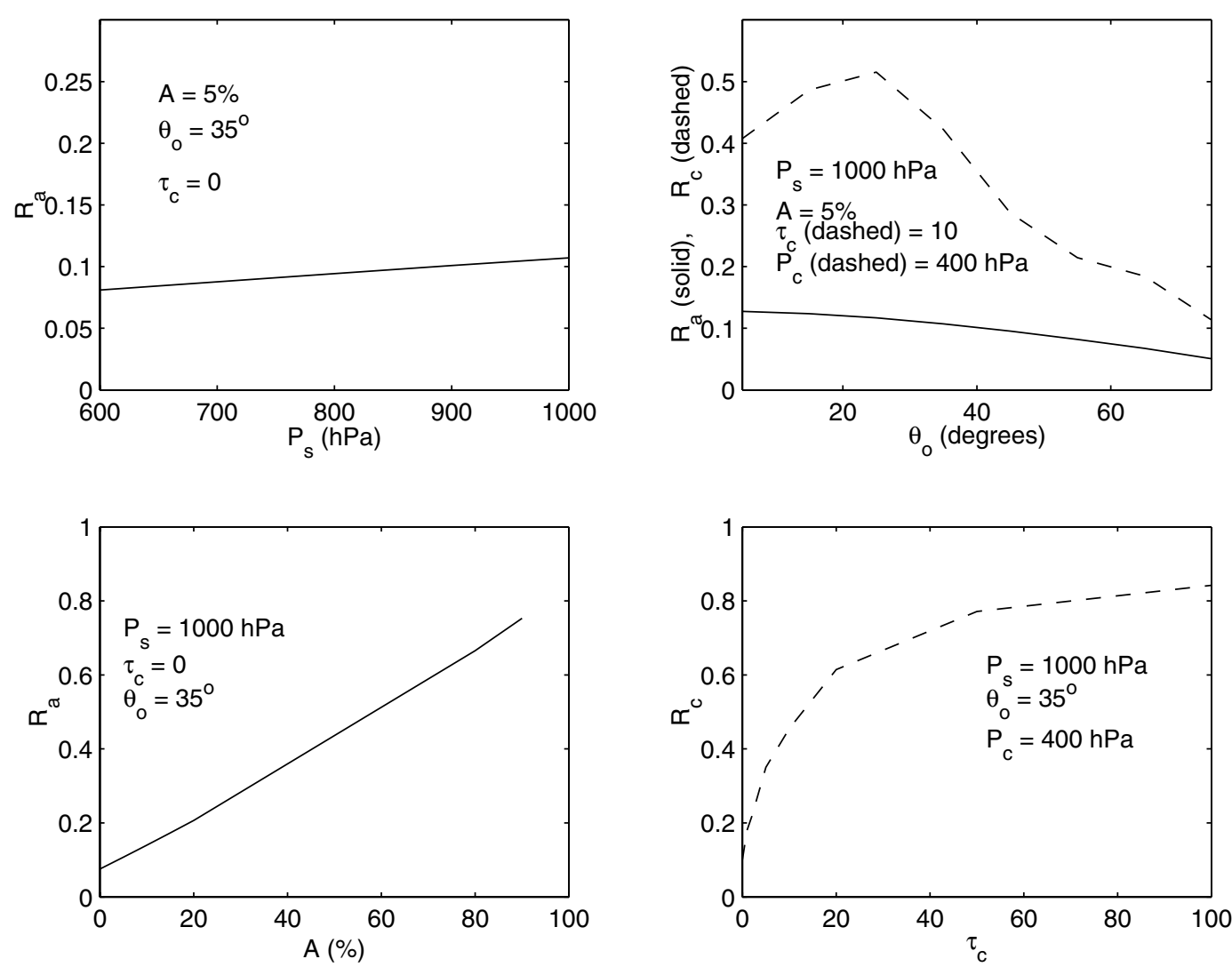

Figure 3. Solar reflectivity at $437 \mathrm{~nm}$ for a nadir viewing satellite instrument for clear sky $\left(R_{a}\right)$ and cloudy sky $\left(R_{c}\right)$ (equations (9)). The plots show the dependencies of $R_{a}$ and $R_{c}$ on surface pressure $P_{s}$, solar zenith angle $\theta_{o}$, surface albedo $A$, and cloud optical thickness $\tau_{c}$, with all other variables referenced to a standard case $\left(P_{s}=1000 \mathrm{hPa}, \theta_{o}=35^{\circ}, A=5 \%, \tau_{c}=0\right.$ or 10 , and cloud top pressure $\left.P_{c}=400 \mathrm{hPa}\right)$.

of $\mathrm{NO}_{2}$ near the surface as compared to $65 \%$ at $800 \mathrm{hPa}$, and $\sim 100 \%$ at $300 \mathrm{hPa}$. Calculations of $w_{c}(\sigma)$ are shown for illustrative cloud top pressures of $800 \mathrm{hPa}$ for the Pacific scene (stratus) and $600 \mathrm{hPa}$ for the Pennsylvania scene. Both clouds have an optical thickness of 10 and hence a pressure thickness of $125 \mathrm{hPa}$. Above the cloud $w_{c}(\sigma)$ is enhanced with respect to $w_{a}(\sigma)$ but the opposite is true below the cloud [Koelemeijer and Stammes, 1999; Richter and Burrows, 2002]. Above the cloud $w_{c}(\sigma)$ is larger than 1 due to multiple scattering. Little sensitivity to cloud top pressure is exhibited by $w_{c}(\sigma)$ above cloud top.

[23] The shape factors in Figure 2 illustrate the range of vertical distributions of $\mathrm{NO}_{2}$ : minima in the boundary layer over remote oceans (bottom right) and maxima in the boundary layer over continental source regions (top right). The product $w_{a}(\sigma) S(\sigma)$ indicates that slant columns observed by GOME in clear-sky conditions are mostly determined by $\mathrm{NO}_{2}$ in the free troposphere over remote oceans, and by $\mathrm{NO}_{2}$ in the boundary layer over continental source regions. For clear-sky conditions in both cases, $\mathrm{AMF}_{a}$ is less than $\mathrm{AMF}_{\mathrm{G}}$ because of the decrease in sensitivity toward the surface. For cloudy conditions, the slant columns observed by GOME are primarily from $\mathrm{NO}_{2}$ within and above the cloud. As a result $\mathrm{AMF}_{c}$ can be larger than $\mathrm{AMF}_{a}$ if little $\mathrm{NO}_{2}$ is below the cloud (bottom right) or can be smaller than $\mathrm{AMF}_{a}$ if the cloud obscures boundary layer $\mathrm{NO}_{2}$ (top right).
[24] Figure 3 shows the dependence of the clear-sky and cloudy reflectivities $\left(R_{a}\right.$ and $\left.R_{c}\right)$ on surface pressure $P_{s}$, solar zenith angle $\theta_{o}$, surface albedo A, and cloud optical thickness $\tau_{c}$, again for an illustrative case. For low surface albedo $R_{a}$ increases linearly with surface pressure due to increasing Rayleigh scattering optical depth. The dependence of $R_{a}$ on surface pressure decreases with increasing surface albedo, becoming nearly independent of surface pressure for a surface albedo greater than $80 \%$ (not shown). Similarly, $R_{c}$ exhibits little variation with cloud top pressure (not shown). The top right panel in Figure 3 shows the decrease of $R_{a}$ with increasing $\theta_{o}$. Although Rayleigh optical depth increases with $\theta_{o}$, the Rayleigh scattering phase function is forward and backward peaked, scattering less radiation sideways toward the nadir when $\theta_{o}$ increases. The phase function for Mie scattering cloud droplets is more strongly peaked with more angular features, hence the more pronounced relationship between $R_{c}$ and $\theta_{o}$. The bottom left panel in Figure 3 shows that $R_{a}$ has a near-linear relationship with $A$. Calculations for a zero surface albedo show that Rayleigh scattering alone produces $R_{a}$ of about $10 \%$. Figure 3 (bottom right) illustrates that $R_{c}$ is a strong function of $\tau_{c}$, especially for $\tau_{c}$ less than 20, beyond which $R_{c}$ approaches an asymptotic value. The asymptotic value decreases as $\theta_{o}$ increases.

[25] We calculate the AMF for each individual GOME observation scene in July 1996 as a function of local $P_{s}, A$, $\theta_{o}, \theta, f, \tau_{c}$, and $P_{c}$, using tabulated values of $\left(w_{a}, w_{c}\right)$ and 
July Mean $\mathrm{AMF}_{\mathrm{a}}$
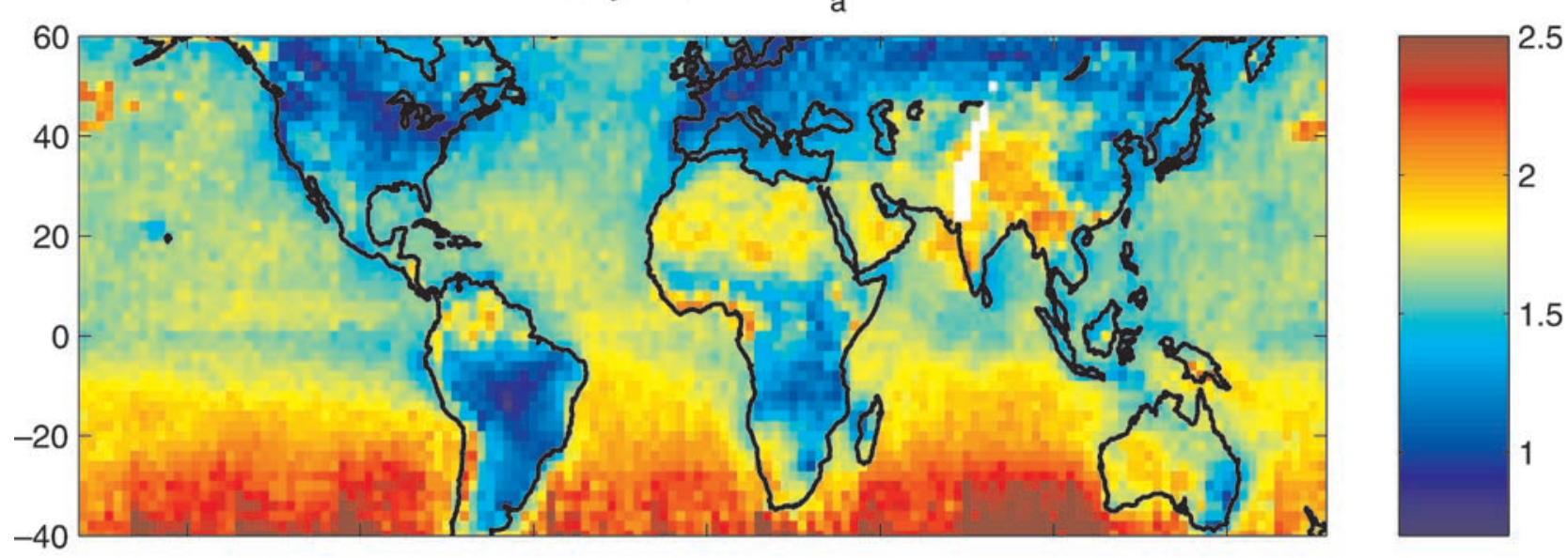

July Mean Fraction of I from Clouds
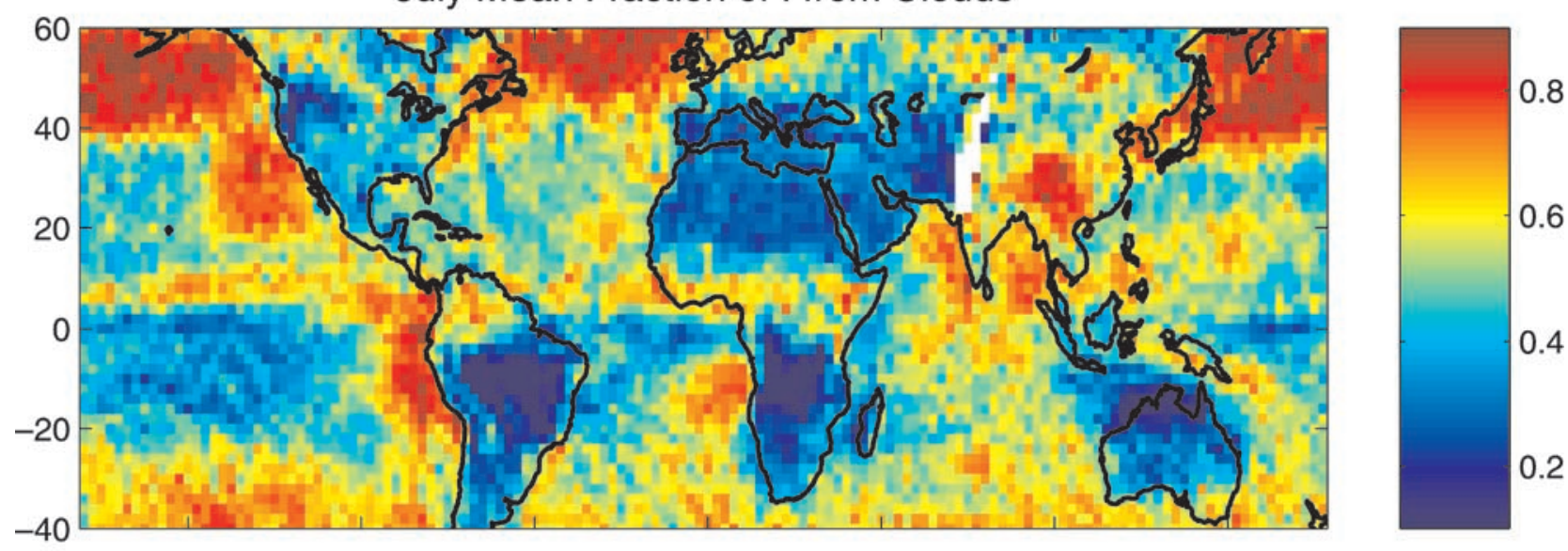

July Mean AMF

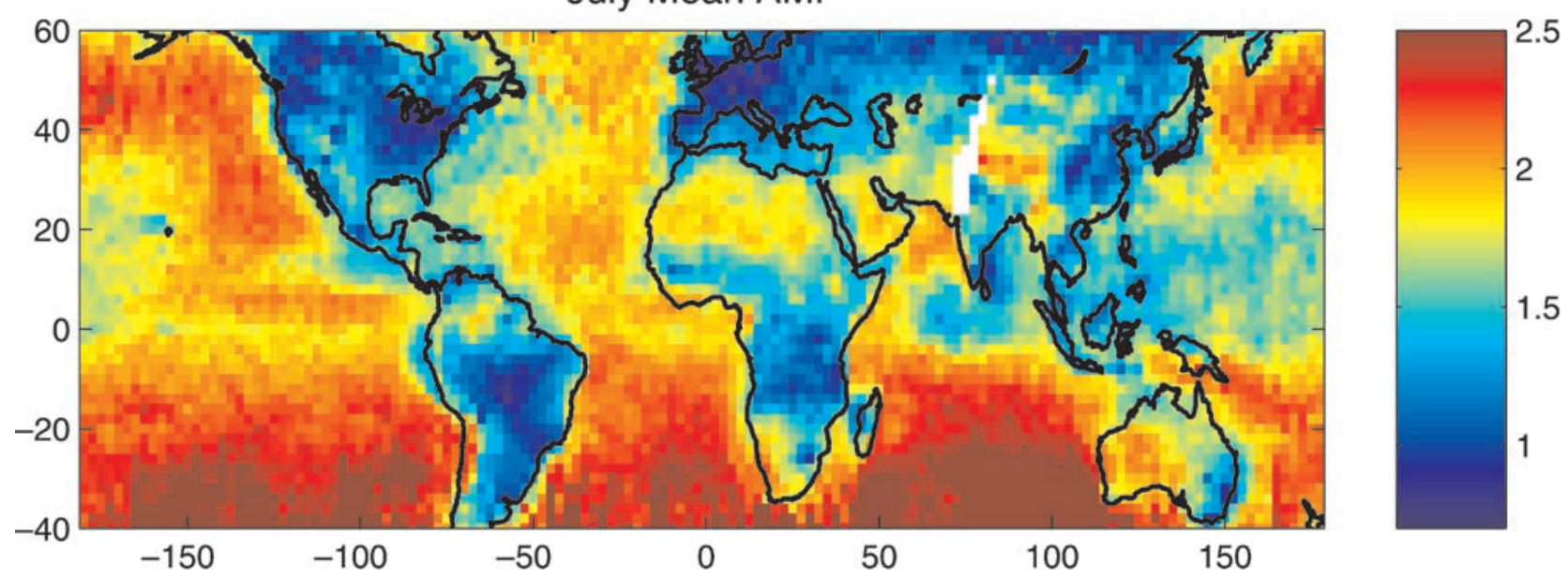

Figure 4. (top) Clear-sky AMF (equation (7a)). (middle) Fraction of GOME backscattered radiance contributed by clouds (equation (12)). (bottom) Actual AMF accounting for clouds (equation (11)). Values are means for July 1996. There are no GOME data for the white area over central Asia due to the absence of GOME observations during normal ERS-2 tape recorder operations. 


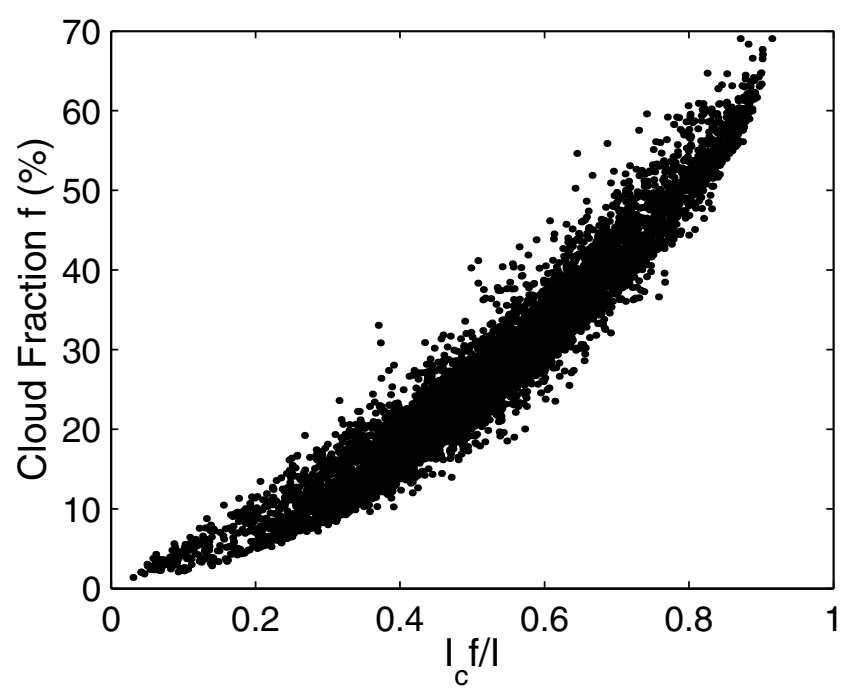

Figure 5. Relationship between GOMECAT cloud fraction and the fraction of the backscattered radiance from clouds (equation (12)) for the ensemble of GOME scenes in July 1996.

$\left(R_{a}, R_{c}\right)$ as described above together with equations (7) and (11). We discard scenes with an AMF less than 0.5 (less than $0.1 \%$ of the total observations) to remove outliers with high cloud fraction, low cloud top pressure, and high optical thickness that obscure the bulk of tropospheric $\mathrm{NO}_{2}$. Global $\mathrm{AMF}_{a}$ values (Figure 4, top) are generally in the range $0.8-1.5$ over vegetated land surfaces, and 1.5-2.5 over ocean. Surface $\mathrm{NO}_{\mathrm{x}}$ emissions from anthropogenic activity, soils, and biomass burning introduce a steep vertical gradient in $\mathrm{NO}_{2}$ concentrations almost everywhere over land; $\mathrm{NO}_{2}$ profiles over oceans typically show less vertical gradient (Figure 2). Arid (deep boundary layers and high surface albedos) and intensely convective continental regions are exceptions characterized by relatively high AMFs. The latter are biased high from contamination of the surface albedos by persistent clouds over the monsoon regions of southeast Asia, the Ivory Coast of Africa, northern South America, New Guinea, and over the North Pacific (near $45^{\circ} \mathrm{N}, 180^{\circ} \mathrm{E}$ ). The coefficient of variation (standard deviation divided by the monthly mean value for July 1996) of the $\mathrm{AMF}_{a}$ is less than a few percent, implying that temporal variability in the shape factors from the GEOS-CHEM model has little influence on the retrieval.

[26] Figure 5 shows the relative contribution of clouds to the backscattered radiance $I$ seen by GOME, as determined from

$$
\frac{I_{c} f}{I}=\frac{R_{c} f}{R_{o}(1-f)+R_{c} f}
$$

Generally when $f$ is greater than $25 \%$, over $50 \%$ of $I$ is from the cloudy subscene. Variability in cloud optical thickness and surface albedo induces scatter in the relationship between $I_{c} f / I$ and $f$ (Figure 5). Figure 4 (middle) shows the spatial structure in $I_{c} f / I$. Clouds contribute more than $60 \%$ of $I$ over cloudy regions such as the high-latitude oceans, the intertropical convergence zone (ITCZ), the
Asian monsoon region, and the stratus-covered oceans off the west coasts of southern Africa, South America, and North America. Clouds are less persistent over continents so that $I_{c} f / I$ is relatively small and most of the backscattered radiance seen by GOME is from the clear-sky fractions of the scenes.

[27] Figure 4 (bottom) shows the actual mean AMF values for July 1996 accounting for cloud scattering as calculated with equation (11). The AMF increases by up to $40 \%$ over the oceans relative to $\mathrm{AMF}_{a}$, especially over regions where $I$ is largely from clouds. As illustrated in Figure 2, low stratus decks over the oceans where most of the $\mathrm{NO}_{2}$ is above the stratus enhance the sensitivity of GOME to the $\mathrm{NO}_{2}$ column. Over continental regions with high surface emissions such as the northeastern US and northern Europe, the actual AMF is 20-30\% lower than $\mathrm{AMF}_{a}$ reflecting the obscuration of boundary layer $\mathrm{NO}_{2}$ below clouds. The coefficient of variation of the AMF for July 1996 is generally less than $15 \%$ and always less than $30 \%$; temporal variability in cloud cover has a moderate effect.

\subsection{Comparison With Previous Retrievals}

[28] The AMF calculation presented here improves in several ways over previous $\mathrm{NO}_{2}$ retrievals [Leue et al., 2001; Velders et al., 2001; Richter and Burrows, 2002]. All three previous retrievals assumed a globally uniform $\mathrm{NO}_{2}$ vertical profile in their AMF calculation. As illustrated in Figure 2, $\mathrm{NO}_{2}$ vertical profiles exhibit high spatial variability, resulting in AMF values over land that are about half of ocean values. Previous retrievals also overestimated $\mathrm{NO}_{2}$ columns over regions of high boundary layer depths, and underestimated them over regions of low boundary layer depths.

[29] Lene et al. [2001] used albedos determined over 295$745 \mathrm{~nm}$, resulting in land albedos about 3 times the values used here. Both Velders et al. [2001] and Richter and Burrows [2002] used a globally uniform surface albedo of about $5 \%$, closer to the values used here, but contributing to an overestimate of the $\mathrm{NO}_{2}$ columns over regions of high surface albedo, and an underestimate over regions of low surface albedo. Surface albedo determined from GOME at $440 \mathrm{~nm}$ varies from $2 \%$ over densely vegetated regions such as the Amazon to $10-15 \%$ over deserts such as the Sahara. We find that a $50 \%$ error in the surface albedo over the Pennsylvania scene $(0.04 \pm 0.02)$ yields a corresponding AMF error of up to $28 \%$. Surface albedo is particularly important in determining the sensitivity of GOME to boundary layer $\mathrm{NO}_{2}$.

[30] Richter and Burrows [2002] compared scenes with cloud fractions less than 0.1 and scenes with cloud fraction greater than 0.3 to examine the amount of $\mathrm{NO}_{2}$ above clouds. Leue et al. [2001] and Velders et al. [2001] corrected for scattering by clouds by assuming a uniform cloud reflectivity of about 0.8 and cloud fraction of 0.5 , a correction that increased their tropospheric values by about 4 . However, cloud reflectivity is highly dependent on optical thickness and solar zenith angle (Figure 3 ), and is less than 0.5 for cloud optical thickness less than 10 (Figure 3, bottom right). Cloud fraction is also highly variable. Figure 4 illustrates the high spatial variability in the cloud correction from our method. We find that the actual cloud correction is much smaller than that used by Leue et al. [2001] and Velders et al. [2001] and even variable in sign, increasing tropospheric values by up to $30 \%$ over cloudy land regions but decreasing 


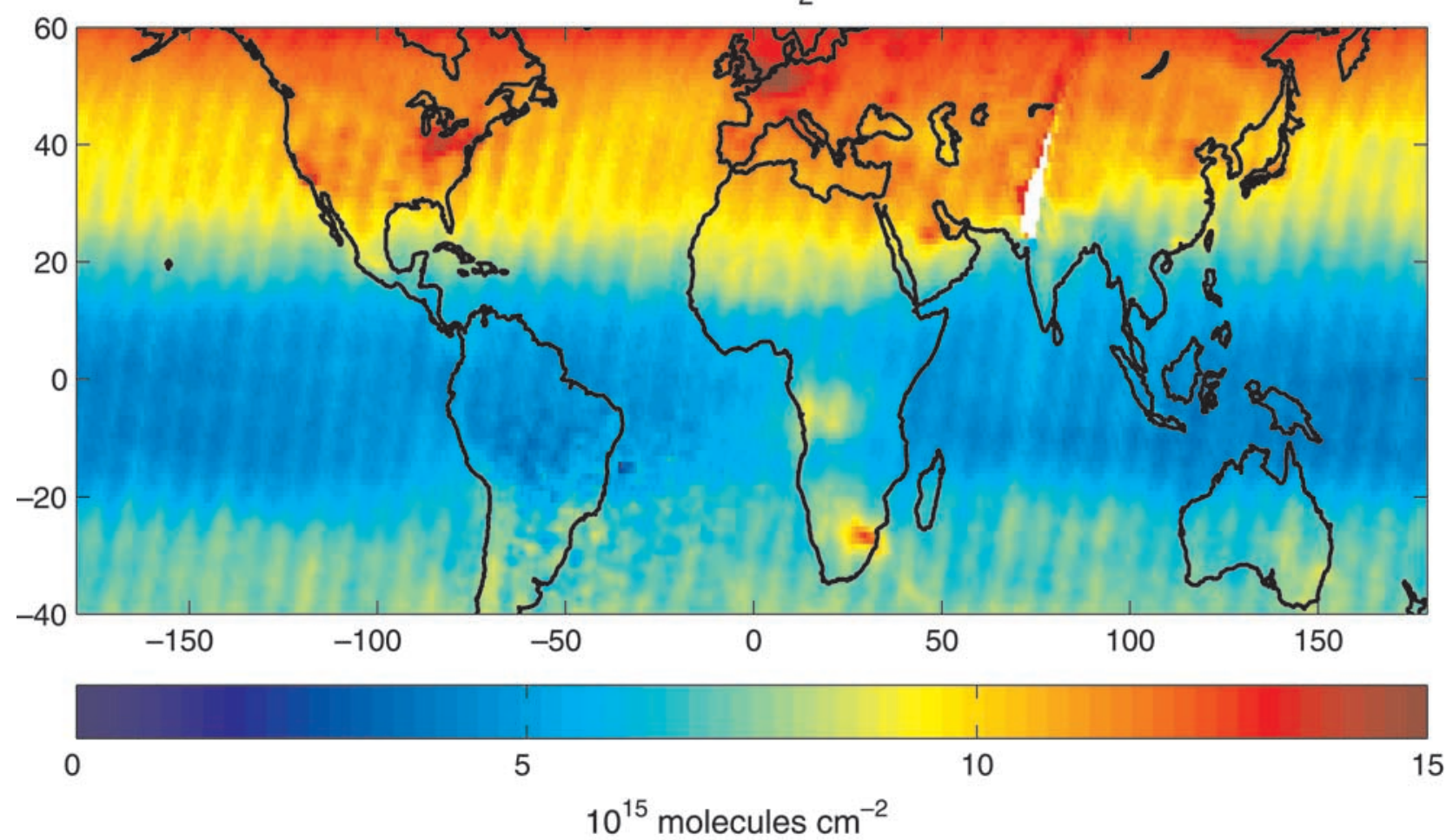

Figure 6. Monthly mean slant columns of $\mathrm{NO}_{2}$ determined from GOME for July 1996. Streaking along orbit paths results from daily variation in the diffuser plate artifact. This artifact is removed in section 5 .

them by up to $40 \%$ over cloudy ocean regions (where most of the $\mathrm{NO}_{2}$ is typically located above the cloud). Although absolute concentrations over ocean are generally small, they are important for conclusions about the amount of $\mathrm{NO}_{2}$ from lightning in the free troposphere as discussed in section 6.2.

\section{Slant Column Fitting}

[31] We determine slant columns of $\mathrm{NO}_{2}$ by directly fitting backscattered radiance spectra observed by GOME, as described by Chance [1998]. No high-pass filtering or smoothing is applied. A nonlinear least squares inversion based on the Levenberg-Marquardt method [Press et al., 1986] retrieves slant column amounts that minimize the $\chi^{2}$ error between observed and calculated backscattered radiance over the wavelength region $423.08-451.23 \mathrm{~nm}$. Backscattered radiances are calculated from solar irradiance spectra, measured reference spectra for the interfering species $\mathrm{O}_{3}$ [Burrows et al., 1999b], $\mathrm{NO}_{2}$ [Burrows et al., 1998], the $\mathrm{O}_{2}-\mathrm{O}_{2}$ collision complex (P. Simon, personal communication, 1993), and $\mathrm{H}_{2} \mathrm{O}$ [Rothman et al., 1998], as well as the Ring effect and the $\mathrm{H}_{2} \mathrm{O}$-ring effect. The Ring effect is determined as described by Chance and Spurr [1997], including both pure Raman scattering of the Fraunhofer spectrum and the contribution from interference by atmospheric absorption. The $\mathrm{H}_{2} \mathrm{O}$-ring effect, or the filling in of Fraunhofer lines by Raman scattering in the librational bands of liquid $\mathrm{H}_{2} \mathrm{O}$ [Walrafen, 1967; Kattawar and Xu, 1992; Gordon, 1999], is calculated by convolving Raman cross sections with a high resolution Fraunhofer spectrum following the work of Chance and Spurr [1997].
Ozone is first fitted separately between 324.93 and 335.09 $\mathrm{nm}$ and held at this fitted value for the $\mathrm{NO}_{2}$ fitting step.

[32] The $\mathrm{NO}_{2}$ spectra are available at temperatures of $221 \mathrm{~K}, 241 \mathrm{~K}, 273 \mathrm{~K}$, and $293 \mathrm{~K}$ [Burrows et al., 1998]. The magnitude of the spectral features in the $293 \mathrm{~K}$ $\mathrm{NO}_{2}$ spectrum are about $80 \%$ of those in $221 \mathrm{~K} \mathrm{NO}$ spectrum. Slant columns fitted with the $221 \mathrm{~K} \mathrm{NO}_{2}$ spectrum are about $75-85 \%$ of those fitted with the $293 \mathrm{~K} \mathrm{NO}_{2}$ spectrum, with some spatial variability in this relationship. We use the $293 \mathrm{~K} \mathrm{NO}_{2}$ spectrum more appropriate for tropospheric $\mathrm{NO}_{2}$, which is mostly in the continental boundary layer; the resulting stratospheric $\mathrm{NO}_{2}$ amounts are systematically about $20 \%$ high, but are subtracted from the total column as described below so the error is of no consequence. Previous tropospheric retrievals [Leue et al., 2001; Velders et al., 2001; Richter and Burrows, 2002] used either the $221 \mathrm{~K}$ or $241 \mathrm{~K} \mathrm{NO}_{2}$ spectrum more appropriate for stratospheric $\mathrm{NO}_{2}$.

[33] Wavelength calibration of the GOME backscattered radiance and solar irradiance spectra is improved using cross-correlation with the Fraunhofer reference spectrum [Caspar and Chance, 1997]. The aliasing introduced from severe spectral undersampling of the GOME instrument and differences between the instrument transfer functions for backscattered radiance and solar irradiance are largely corrected with an undersampling spectrum generated from the high resolution Fraunhofer reference spectrum [Chance, 1998]. The remaining common mode residual, determined as an average fitting residual over a complete orbit, apparently arises from instrumental artifacts (including an imperfect undersampling correction). The common mode residual 


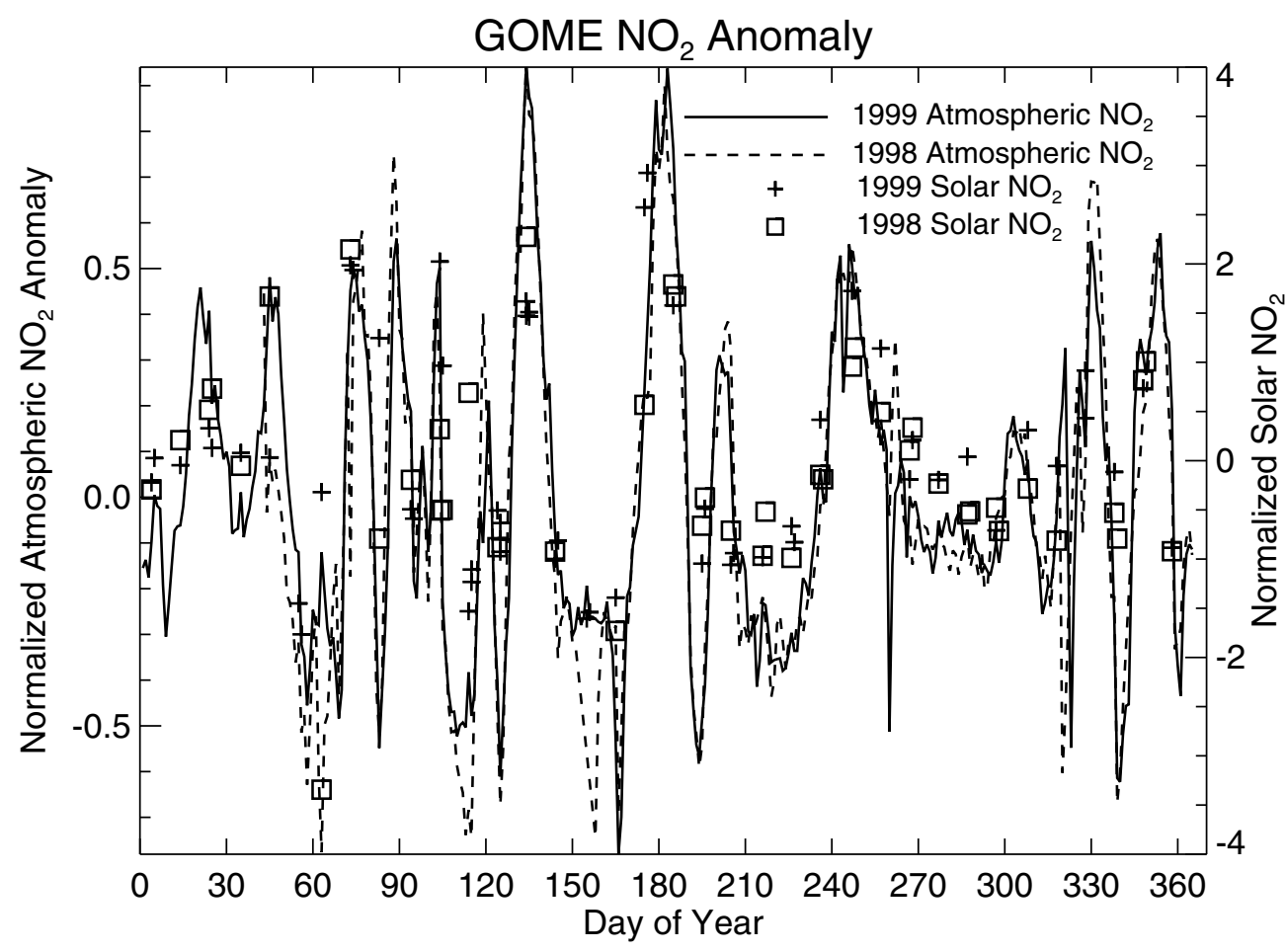

Figure 7. Evidence for the diffuser plate artifact. The dashed and solid lines show the normalized offset in atmospheric $\mathrm{NO}_{2}$ slant columns determined from GOME for 1998 and 1999, respectively. The square and plus, are "solar $\mathrm{NO}_{2}$ " fitted using the solar spectrum for 1 January 1998 as a reference. There is no known $\mathrm{NO}_{2}$ in the sun.

is included in the inversion, improving the fitting precision by roughly a factor of 3 . Slant columns fitted with and without the common mode residual differ by roughly $\pm 5 \times$ $10^{13}$ molecules $\mathrm{cm}^{-2}$, less than $1 \%$ of the northern midlatitude column and up to a few percent of the tropical column. The standard deviation of scene-to-scene variation in $\mathrm{NO}_{2}$ slant columns over the Pacific Ocean is about half of the fitting precision determined with the common mode included and $1 / 6$ of the fitting precision without the common mode. Accounting for the common mode residual represents better the actual fitting precision.

[34] The resulting slant columns of $\mathrm{NO}_{2}$ are illustrated in Figure 6. Only observations from the forward scan are included. There are about 14 orbits daily, each at $25^{\circ}$ intervals. Streaking along orbit paths results not from fitting errors, but rather from the observation of adjacent orbits by GOME on different days and daily variation in the diffuser plate artifact [Richter et al., 2002] as discussed further below. The poleward increase arises from the stratospheric $\mathrm{NO}_{2}$ column. Tropospheric signals are manifest over the northeastern US, Europe, central Africa, South Africa, and other regions. Slight speckle in the $\mathrm{NO}_{2}$ columns can be seen over southern Brazil and the western South Atlantic, a region of high standard deviation in the $\mathrm{NO}_{2}$ columns that is collocated with the South Atlantic Anomaly. The slant columns (determined with a $293 \mathrm{~K} \mathrm{NO}_{2}$ spectrum) are within $30 \%$ of the operational data product (determined with a $241 \mathrm{~K} \mathrm{NO}_{2}$ spectrum) [Thomas et al., 1998]. The $\mathrm{NO}_{2}$ fits have residual RMS values typically $8 \times 10^{-4}$ of the GOME backscattered radiance spectrum. The mean $\mathrm{NO}_{2}$ slant column fitting precision is $1.1 \times 10^{15}$ molecules $\mathrm{cm}^{-2}$
( $1 \sigma$ uncertainties are used throughout). Slant columns determined with a $221 \mathrm{~K} \mathrm{NO}_{2}$ spectrum (appropriate for stratospheric $\mathrm{NO}_{2}$ ) have a fitting precision of $8 \times 10^{14}$.

[35] The diffuser plate of the GOME instrument, used to attenuate solar radiation and enable the same detector to view both the Sun and the Earth, introduces small temporally varying spectral features into the solar irradiance spectra [Richter et al., 2002] (Richter and Wagner, personal communication, 2001). The spectral features vary with solar azimuth angle resulting in a temporally varying offset in the retrieved $\mathrm{NO}_{2}$ slant column densities of up to $\pm 2 \times 10^{15}$ molecules $\mathrm{cm}^{-2}$. This effect can be seen in the streaking pattern of Figure 6. Figure 7 illustrates the anomaly for 1998 and 1999 as the daily departure of retrieved $\mathrm{NO}_{2}$ vertical columns from the annual mean averaged over $10^{\circ} \mathrm{S}$ to $10^{\circ} \mathrm{N}$ and $45^{\circ} \mathrm{E}$ to $270^{\circ} \mathrm{E}$. The offset is remarkably consistent from year to year, although it has no periodicity during 1 year. Evidence that the source of the anomaly is contamination of the solar irradiance spectra by the diffuser plate can be seen in the "solar $\mathrm{NO}_{2}$ " data plotted over the curves in Figure 7. These data were obtained by fitting daily GOME solar irradiance spectra for $\mathrm{NO}_{2}$, using the 1 January 1998 solar irradiance spectrum as a reference. Since $\mathrm{NO}_{2}$ features are not intrinsic to actual solar irradiance spectra, we believe its apparent presence here is an artifact of the diffuser plate. Similar artifacts, not specific to GOME $\mathrm{NO}_{2}$ fitting, have been observed in the laboratory and may affect all instruments that use ground aluminum diffuser plates [Richter et al., 2002] (Richter and Wagner, personal communication, 2001). Other potential sources of the artifact were considered and discarded, including the GOME optical bench temper- 
ature, cooler instrument warming cycles, and time-dependent level 1 calibration adjustments. Removal of the diffuser plate artifact should be performed daily, as this is the timescale for the solar irradiance measurements.

\section{Removal of the Stratospheric Column and Diffuser Plate Artifact}

[36] We define the "nontropospheric" column of $\mathrm{NO}_{2}$ as the sum of the stratospheric column and instrument biases such as the diffuser plate artifact. We remove this column in a two-step process. First, we determine its amount using GOME observations over Pacific regions where tropospheric $\mathrm{NO}_{2}$ is particularly low (but not zero; we subsequently correct for the resulting bias). Second, we assume it is longitudinally invariant and subtract it from the total columns in the corresponding latitude band. Errors associated with each step are discussed.

\subsection{Determination of the Nontropospheric Column}

[37] We determine the latitude-dependent nontropospheric column from GOME data over Pacific regions where tropospheric $\mathrm{NO}_{2}$ is particularly low. We use the GEOS-CHEM model to identify favorable regions. Figure 8 (top) shows monthly mean tropospheric $\mathrm{NO}_{2}$ slant columns calculated from the product of the AMF (Figure 4, bottom) and GEOS-CHEM tropospheric vertical columns. We determine the nontropospheric slant column for each GOME scan angle on a daily timescale and for each $2^{\circ}$ latitude band as the zonal mean $\mathrm{NO}_{2}$ column over the Pacific region within the white lines, excluding Hawaii. Scattering weights in the stratosphere are nearly independent of tropospheric clouds or surface albedo, an important consideration for being able to determine a mean stratospheric slant column; stratospheric scattering weights calculated for high reflectivity scenes $(R=0.8)$ are only about $1 \%$ greater than low reflectivity scenes $(R=0.1)$.

[38] The resulting monthly mean nontropospheric slant columns over the Pacific are shown in Figure 9 (top) as a function of latitude. Figure 9 (bottom) illustrates the temporal variation in the nontropospheric slant columns arising from the diffuser plate artifact for three different latitudes. There are no known photochemical or dynamical processes that could induce a factor of 2 change in equatorial $\mathrm{NO}_{2}$ over a 15-day period. All latitudes generally vary together, as would be expected from an artifact that affects only the solar spectrum. The artifact decreases by up to $5 \times 10^{14}$ molecules $\mathrm{cm}^{-2}$ day $^{-1}$ near 7 July. Averaging the nontropospheric column for subtraction on a 2-day timescale (instead of 1 day as done here) would decrease the measurement accuracy.

[39] An alternative approach to remove the diffuser plate artifact uses a single solar spectrum in the spectral fitting [Richter and Burrows, 2002]. Like the procedure described in the current study, this method also reduces the streaking in total slant columns apparent in Figure 6. However, we find that using a single solar spectrum increases the spectral fitting uncertainty, and it is still optimal to subtract the nontropospheric column at daily intervals to reduce other instrument artifacts.

[40] We determine the nontropospheric column for each latitude band from about 17 observations over the North Pacific and up to 70 observations in the tropics. The slant column fitting precision is typically $1.1 \times 10^{15}$ molecules $\mathrm{cm}^{-2}$ for each observation. The corresponding error decreases as $1 / \sqrt{n}$ yielding a precision between $1.3 \times$ $10^{14}$ and $2.7 \times 10^{14}$ molecules $\mathrm{cm}^{-2}$, where $n$ is the number of observations. Determining the nontropospheric column over a narrower longitudinal or latitudinal region decreases the precision but does not significantly change the accuracy.

[41] Although tropospheric $\mathrm{NO}_{2}$ slant columns over the Pacific are about an order of magnitude less than total slant columns, a latitudinally varying bias is introduced by the assumption of zero tropospheric $\mathrm{NO}_{2}$ over the Pacific. An even larger bias would result from applying this assumption over other oceanic regions such as the North Atlantic, as done by Leue et al. [2001] and Velders et al. [2001], and is the likely cause of the negative values of tropospheric $\mathrm{NO}_{2}$ columns over the oceans in their retrievals. Marine stratus decks over oceans contribute to the bias by increasing the sensitivity of GOME to tropospheric $\mathrm{NO}_{2}$.

[42] Tropospheric $\mathrm{NO}_{2}$ slant columns over the Pacific (Figure 8, bottom) would introduce a latitudinally dependent bias on the nontropospheric slant column if ignored. We subtract them from the nontropospheric column derived for the corresponding latitude and for individual days using the GEOS-CHEM model results over the Pacific for that day (the monthly mean GEOS-CHEM fields are shown in the bottom panel of Figure 8). The $\mathrm{NO}_{2}$ concentrations simulated by GEOS-CHEM over the Pacific are generally high (up to a factor of 2) compared with aircraft observations (e.g., Figure 1). The error introduced by the correction is discussed in section 7 .

\subsection{Zonal Invariance Assumption}

[43] We subtract the nontropospheric column from each latitude for each scan angle on a daily timescale determined by each new GOME solar observation. We assume this column value to be zonally invariant. The assumption of zonal invariance introduces much less error with $\mathrm{NO}_{2}$ than with ozone because most of the $\mathrm{NO}_{2}$ column is in the middle stratosphere [Gordley et al., 1996], whereas ozone is in the lower stratosphere and therefore more affected by zonal variability in transport and in the tropopause.

[44] We quantify the error associated with the assumption of zonally invariant stratospheric columns using $\mathrm{NO}_{2}$ measurements from HALOE data [Russell et al., 1993]; we use version 19 data here. Each UARS yaw cycle is about 36 days long during which time HALOE observations span approximately $60^{\circ} \mathrm{S}$ through $60^{\circ} \mathrm{N}$. Observations by HALOE progress approximately $5^{\circ}$ in latitude while taking about 15 observations at successive longitudes around the world. We calculate stratospheric columns of $\mathrm{NO}_{2}$ from the GEOS-CHEM model tropopause to $1 \mathrm{hPa}$ for each HALOE profile from yaw cycles that include the month of July for the years 1996-2000. Our analysis therefore includes observations from the end of June and the beginning of August. Years prior to 1996 are not included to reduce measurement uncertainty associated with enhanced aerosol concentrations from Mount Pinatubo [Gordley et al., 1996]. Data with uncertainties greater than $1 \times 10^{8}$ molecules $\mathrm{cm}^{-3}$ are excluded, largely removing unreal increases near the bottom of profiles [Gordley et al., 1996]. Number densities of $\mathrm{NO}_{2}$ peak between 5 and $40 \mathrm{hPa}$; the resulting underestimate in stratospheric $\mathrm{NO}_{2}$ columns from the 


\section{July 1996 Tropospheric $\mathrm{NO}_{2}$ Slant Columns from GEOS-CHEM}
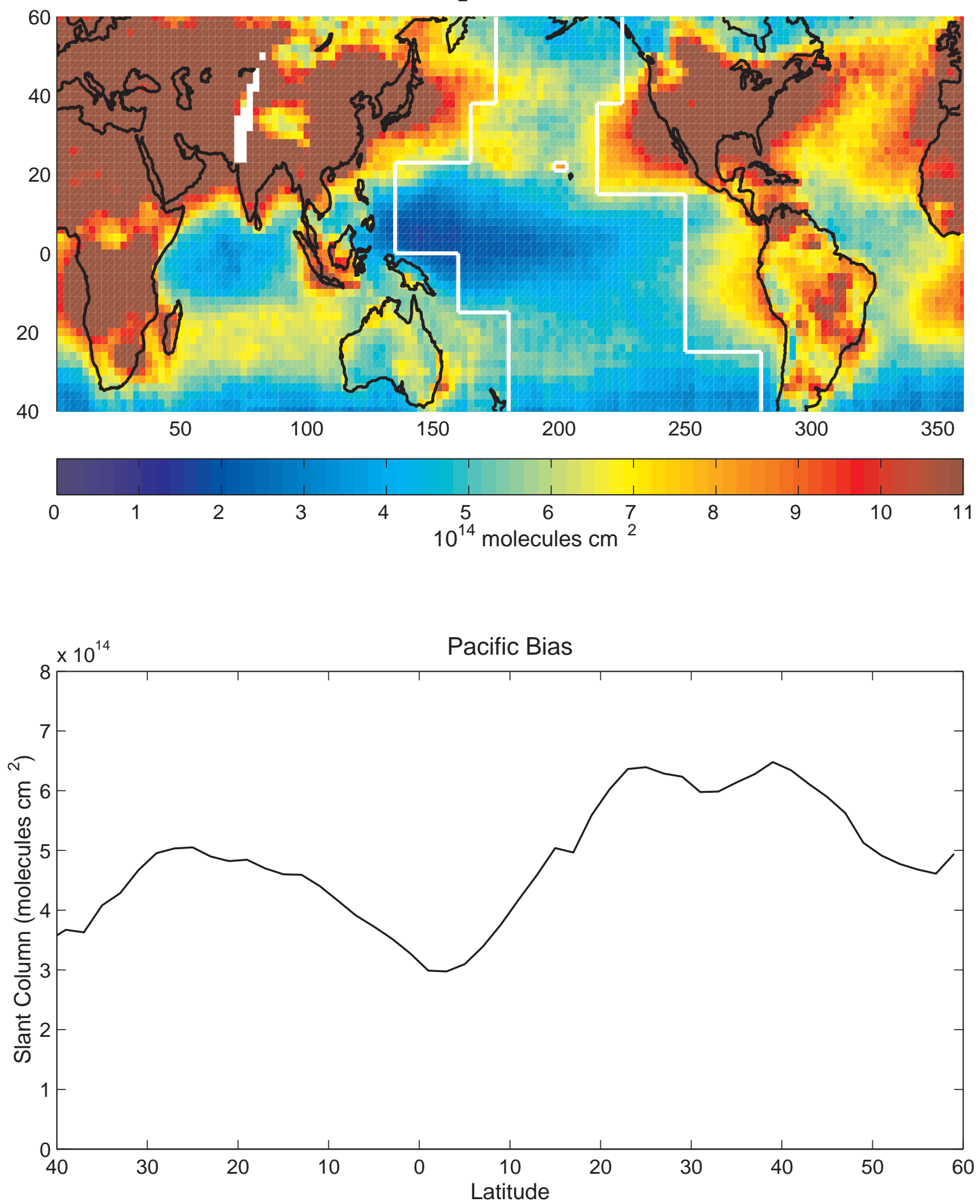

Figure 8. (top) Monthly mean tropospheric $\mathrm{NO}_{2}$ slant columns simulated with the GEOS-CHEM model for July 1996. The white lines bound the central Pacific region of low tropospheric $\mathrm{NO}_{2}$ used to determine the nontropospheric column for a given latitude. The maximum on the color scale corresponds to the GOME fitting precision and thus identifies regions where tropospheric $\mathrm{NO}_{2}$ can be observed. GEOS-CHEM fields for the source regions are shown in Figure 12. (bottom) Tropospheric $\mathrm{NO}_{2}$ slant columns over the central Pacific, averaged over the region bounded by the white lines and plotted as a function of latitude for July 1996. These columns represent a latitudinal bias introduced by the assumption of zero tropospheric $\mathrm{NO}_{2}$ over the Pacific, and the bias is corrected as described in the text. 
July Mean Nontropospheric Slant Column

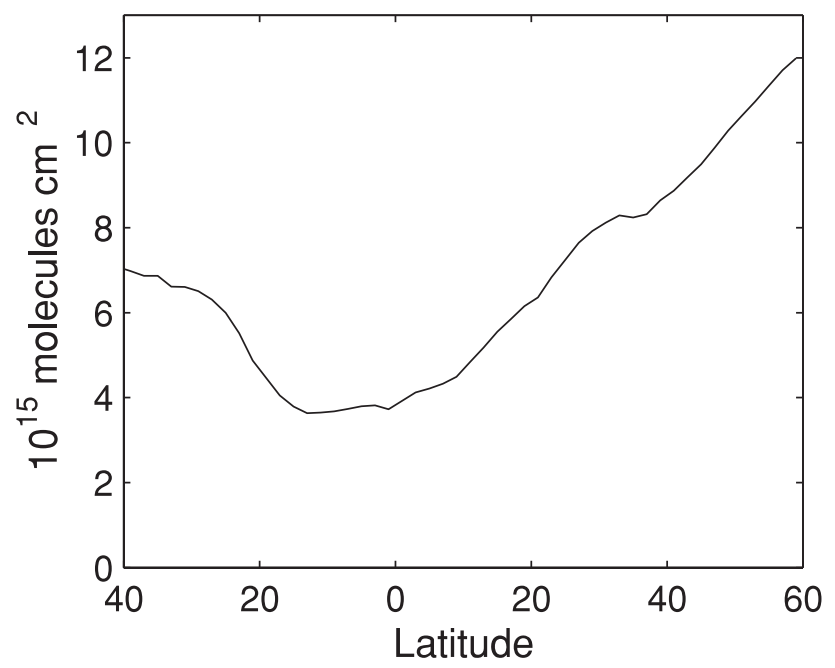

Daily Mean Nontropospheric Slant Column

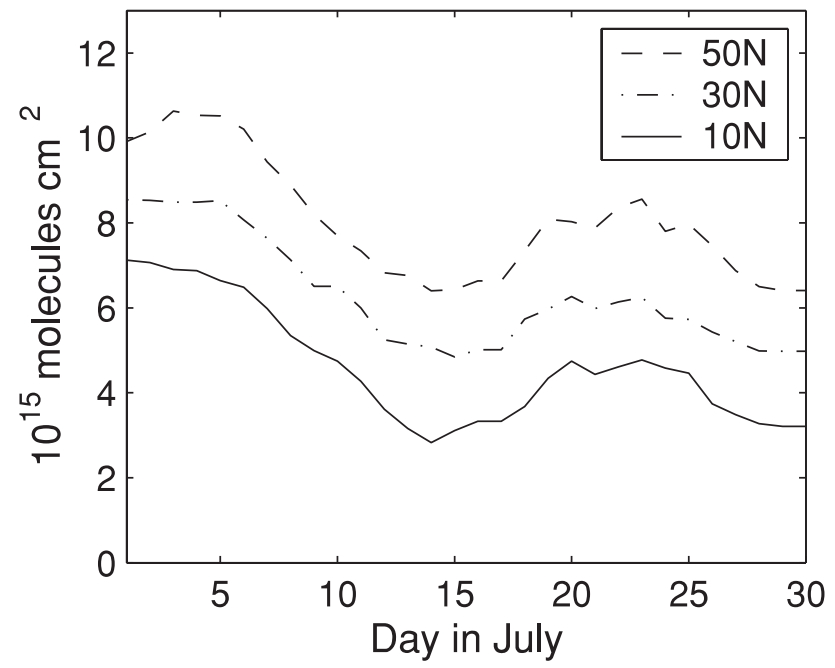

Figure 9. (top) July 1996 mean nontropospheric slant columns of $\mathrm{NO}_{2}$ determined from GOME observations over the Pacific. (bottom) Daily variability in these columns determined from GOME observations over the Pacific for three different latitudes.

removal of high-uncertainty, lower-stratospheric values should be less than a few percent.

[45] We calculate means and standard deviations of the HALOE observations for each set of approximately 15 observations at different longitudes within a $5^{\circ}$ latitude band. Figure 10 shows the standard deviations, which are a measure of zonal variability, as a function of latitude for sunrise and sunset. The standard deviation is minimum at the equator $\left(1 \times 10^{14}\right.$ molecules $\left.\mathrm{cm}^{-2}\right)$ and remains below $4 \times$ $10^{14}$ molecules $\mathrm{cm}^{-2}$ at all latitudes. It is less than the GOME vertical column fitting precision, calculated as the slant column fitting precision divided by $\mathrm{AMF}_{\mathrm{G}}$. Stratospheric columns of $\mathrm{NO}_{2}$ at the time of GOME overpass $(\sim 1030 \mathrm{AM})$ are about half the sunrise/sunset values [Wennberg et al., 1994]; and the errors should be correspondingly less. The sunset values between $10^{\circ} \mathrm{S}$ and $25^{\circ} \mathrm{S}$ exhibit relatively high standard deviation across all longitudes, not just reflecting the South Atlantic Anomaly. We find no systematic zonal pattern in the HALOE stratospheric $\mathrm{NO}_{2}$ columns for latitudes equatorward of about $65^{\circ}$. Between $65^{\circ} \mathrm{N}$ and $75^{\circ} \mathrm{N}$ systematic maxima appear near $110^{\circ} \mathrm{W}$ and $80^{\circ} \mathrm{E}$ and minima near $20^{\circ} \mathrm{E}$ and $140^{\circ} \mathrm{E}$, about $\pm 4 \times 10^{14}$ molecules $\mathrm{cm}^{-2}$ with respect to the zonal mean (not shown).

\section{Retrieved Tropospheric Columns of $\mathrm{NO}_{2}$ 6.1. Slant Columns}

[46] Figure 11 (top) shows the monthly mean tropospheric residual slant column of $\mathrm{NO}_{2}$ for July 1996. The tropospheric residual exhibits low background $\mathrm{NO}_{2}$ columns over oceans and strong regional enhancements over continents. One of the strongest tropospheric enhancements is seen over the Congo Basin, where considerable biomass burning takes place in July [Scholes et al., 1996]. Over the northeastern US, California, Mexico City, and industrial regions of Europe, tropospheric enhancements are about $50 \%$ of the stratospheric column. Tropospheric enhancements are of comparable magnitude to stratospheric columns over Saudi Arabia, the biomass burning region of Central Africa, and the Transvaal region of South Africa, a major region of electricity generation. Table 2 shows that the GOME tropospheric slant columns exhibit a high degree of consistency with GEOSCHEM vertical columns over the entire world $(r=0.63, n=$ $7170, \mathrm{p}<0.005)$ and especially over the United States $(\mathbf{r}=$ $0.75, \mathrm{n}=288, \mathrm{p}<0.005$ ), even before model information has been passed to the GOME product through the AMF calculation. The Pearson's correlation coefficient is unchanged if the bias correction (Figure 8, bottom) is excluded to completely remove GEOS-CHEM influence.

[47] We have pointed out previously the sensitivity of the GOME observations to clouds, which enhance the sensitivity to $\mathrm{NO}_{2}$ above clouds (as typically occurs over oceans), and obscure $\mathrm{NO}_{2}$ below cloud (as typically occurs over continental source regions). The former effect is particularly obvious over the South Atlantic downwind of the Congo Basin (Figure 11), where biomass burning outflow is transported above a persistent stratus deck [Bachmeier and Fuelberg, 1996]. A similar effect over the region was noted in ozone retrievals from TOMS [Thompson et al., 1993]. Slant columns are generally higher over source regions such as the northeastern US, northern Europe, and eastern Asia where most $\mathrm{NO}_{2}$ is in the boundary layer and masked by overhead clouds. We find further evidence of these cloud effects through correlations of the tropospheric $\mathrm{NO}_{2}$ slant columns with GOMECAT cloud fractions. Over the northeastern United States, GOMECAT cloud fraction explains approximately $50 \%$ of the variance in tropospheric $\mathrm{NO}_{2}$ slant columns $(\mathbf{r}=-0.71, \mathrm{n}=1140, \mathrm{p}<0.005)$. In contrast, $\mathrm{NO}_{2}$ columns over oceans are usually positively correlated with clouds because most $\mathrm{NO}_{2}$ over oceans is in the free troposphere [Bradshaw et al., 1999] and its detection is enhanced by reflectivity from low stratus clouds. We observe this over the South Pacific, where cloud fraction explains approximately $25 \%$ of the variance in $\mathrm{NO}_{2}$ tropospheric slant columns $(\mathbf{r}=0.48, \mathrm{n}=40377, \mathrm{p}<0.005)$.

\subsection{Vertical Columns}

[48] We regrid the GOME slant columns onto the GEOSCHEM model grid of $2^{\circ}$ latitude by $2.5^{\circ}$ longitude, and 


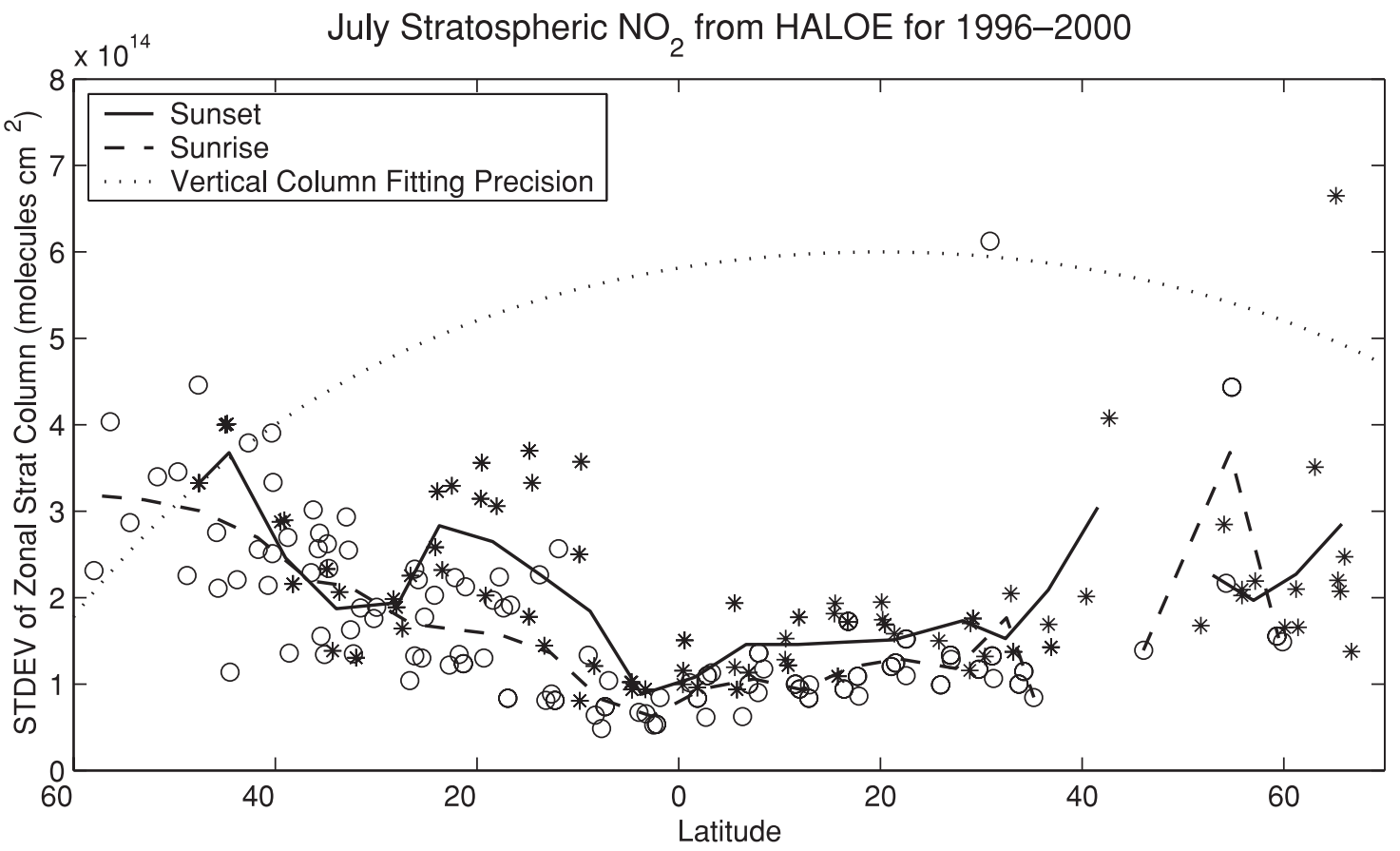

Figure 10. Zonal standard deviation of stratospheric $\mathrm{NO}_{2}$ columns (tropopause to $1 \mathrm{hPa}$ ) calculated from HALOE profiles for each set of roughly 15 observations in a $5^{\circ}$ latitudinal band for each yaw cycle that includes the month of July for the years 1996-2000. Columns are calculated as described in the text. Sunset values are indicated with stars and sunrise with circles. The solid and dashed lines represent the average standard deviations. The dotted line is the vertical column fitting precision for GOME calculated as the slant column fitting precision of $1.1 \times 10^{15}$ molecules $\mathrm{cm}^{-2}$ divided by $\mathrm{AMF}_{\mathrm{G}}$.

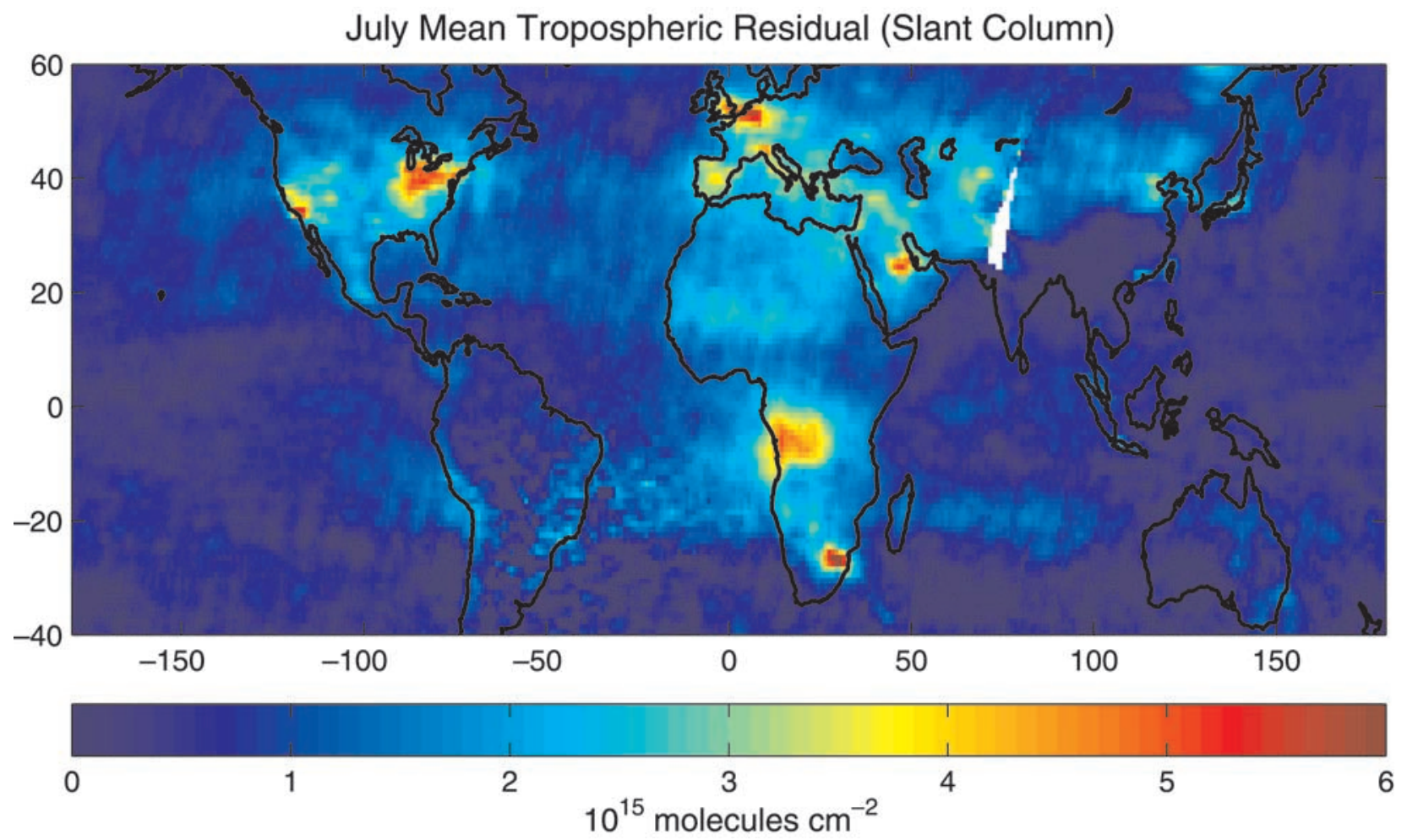

Figure 11. July 1996 mean tropospheric slant column calculated on a daily basis as the difference between total $\mathrm{NO}_{2}$ slant columns and zonal mean $\mathrm{NO}_{2}$ slant columns over the Pacific with bias correction as described in section 5.1 . 
Table 2. Correlation Coefficient (r) Between Modeled (GEOS-CHEM) and Retrieved (GOME) Tropospheric Columns ${ }^{\mathrm{a}}$

\begin{tabular}{lcc}
\hline \multicolumn{1}{c}{ Retrieval Step } & $\begin{array}{c}\text { World } \\
(\mathrm{n}=7170)\end{array}$ & $\begin{array}{c}\text { United States } \\
(\mathrm{n}=288)\end{array}$ \\
\hline Removal of the stratosphere and diffuser plate artifact & 0.63 & 0.76 \\
Correction for the Pacific bias & 0.64 & 0.76 \\
Application of $\mathrm{AMF}_{a}$ & 0.73 & 0.78 \\
Inclusion of clouds in the AMF calculation & 0.76 & 0.78 \\
\hline
\end{tabular}

${ }^{\mathrm{a}}$ All values are statistically significant $(\mathrm{p}<0.005)$.

calculate vertical columns by dividing each tropospheric slant column by the locally derived AMF (section 3). Figure 12 (top) shows the resulting monthly mean tropospheric vertical columns. The spatial distribution is similar to that of the tropospheric slant columns (Figure 11, top). The AMF conversion from slant to vertical columns generally enhances columns over land with respect to those over oceans as discussed previously. It also enhances midlatitude columns with respect to tropical columns due to the higher solar zenith angles and shallower boundary layers at midlatitudes.

[49] Aircraft corridors or regions of intense lightning activity exhibit no $\mathrm{NO}_{2}$ enhancement (Figure 12). Richter and Burrows [2002] attributed enhancements of $\mathrm{NO}_{2}$ slant columns for scenes with cloud fractions greater than $30 \%$ over the tropical Atlantic and Africa to lightning. Although we find similar enhancements in the slant columns (Figure 11) off the west coast of the Congo Basin where persistent stratus decks make GOME particularly sensitive to $\mathrm{NO}_{2}$ transported above the clouds, the enhancements largely disappear with the conversion of slant to vertical columns (Figure 12). In situ observations and the model show high NO mixing ratios in the upper troposphere over the region (top right panel of Figure 1), but the corresponding $\mathrm{NO}_{2}$ number density profile is skewed toward the lower troposphere where surface $\mathrm{NO}_{\mathrm{x}}$ sources likely play a more important role. The cloud fraction threshold of 0.3 used by Richter and Burrows [2002] may not discriminate between upper tropospheric and surface sources since 50\% of backscattered radiance still originates from the clear-sky subscene (Figure 5). To examine the sensitivity of GOME to lightning, we performed a simulation with $6 \mathrm{Tg} \mathrm{NO}_{\mathrm{x}}$ from lightning, twice the magnitude of the standard simulation (Table 1). The resultant GEOS-CHEM monthly mean $\mathrm{NO}_{2}$ columns increased by less than $3 \times 10^{14}$ molecules $\mathrm{cm}^{-2}$ anywhere, well below the fitting uncertainty.

\subsection{Comparison to GEOS-CHEM}

[50] A critical test of the accuracy of the GOME tropospheric $\mathrm{NO}_{2}$ column is its consistency with the GEOSCHEM model results over the United States (Figure 12, middle). The US $\mathrm{NO}_{\mathrm{x}}$ emission inventory used in GEOSCHEM for 1996 is from the Environmental Protection Agency [EPA, 1997], and is believed to be accurate to within 20\% [e.g., Munger et al., 1998]. Simulation of the $\mathrm{NO}_{\mathrm{x}} / \mathrm{NO}_{\mathrm{y}}$ concentration ratio at U.S. sites [Horowitz et al., 1998; Liang et al., 1998] suggests that the lifetime of $\mathrm{NO}_{\mathrm{x}}$ in the model is accurate to within $30 \%$. Therefore we expect agreement between the GOME and GEOS-CHEM $\mathrm{NO}_{2}$ columns to within a combined accuracy of $35 \%$. The July mean GOME column in our retrieval over the United States is $18 \%$ higher than the corresponding value from GEOSCHEM, i.e., within the estimated uncertainty. The GOME vertical columns capture $58 \%$ of the spatial variance in the GEOS-CHEM columns over the United States $(\mathbf{r}=0.78, \mathrm{n}$ $=288, \mathrm{p}<0.005)$ as shown in Table 2 . These results lend confidence to the interpretation of the GOME $\mathrm{NO}_{2}$ retrieval as a proxy for surface $\mathrm{NO}_{\mathrm{x}}$ emissions. The correlation between the GEOS-CHEM model and GOME observations is also remarkable over the rest of the world $(\mathbf{r}=0.76, \mathrm{n}=$ $7170, \mathrm{p}<0.005)$.

[51] In comparing tropospheric $\mathrm{NO}_{2}$ vertical columns from GOME with the GEOS-CHEM model, one has to be concerned about model contamination resulting from the use of GEOS-CHEM shape factors in the AMF calculation. There is really no choice in the matter, since use of shape factors from the model in the AMF calculation is a prerequisite for meaningful comparison of vertical columns [Palmer et al., 2001]. Comparing slant columns would only displace the problem. One must also recognize that the shape factor and the $\mathrm{NO}_{2}$ tropospheric column are two separate pieces of information, and GOME offers only one piece of information. Figure 13 shows the relationship between the AMF and modeled $\mathrm{NO}_{2}$ columns, which quantifies the degree of model contamination in the comparison with observed $\mathrm{NO}_{2}$ columns. Enhanced $\mathrm{NO}_{2}$ columns $\left(>2 \times 10^{15}\right.$ molecules $\left.\mathrm{cm}^{-2}\right)$ have little relationship with the AMF $(\mathbf{r}=-0.14, \mathrm{n}=240)$ since the $\mathrm{NO}_{2}$ shape factor over source regions is largely determined by boundary layer depth. Columns less than $2 \times 10^{15}$ molecules $\mathrm{cm}^{-2}$ exhibit a significant relationship with the AMF $(\mathbf{r}=-0.65, \mathrm{n}=6987, \mathrm{p}<0.005)$ that arises in part from the contrast between $\mathrm{NO}_{2}$ vertical profiles over ocean and land.

[52] Retrieved tropospheric vertical columns exhibit a number of differences with the GEOS-CHEM model columns (Figure 12, bottom). Observations from GOME indicate about $50 \%$ more $\mathrm{NO}_{2}$ over the Transvaal region of South Africa, a major region of electricity generation. Retrieved columns also are higher over the northeastern US and industrial regions of Europe. Observations show less $\mathrm{NO}_{2}$ over Houston, the biomass burning region of central Africa, northern India, and eastern Asia. Neglect of absorbing aerosols in the AMF calculation could contribute to a retrieval underestimate for the latter regions, where soot concentrations are particularly high. A similar problem was reported by Fishman et al. [1996a] in retrieving tropospheric ozone columns from TOMS over biomass burning regions.

[53] The spatial distribution of GOME tropospheric $\mathrm{NO}_{2}$ vertical columns presented by Velders et al. [2001] for July 1997 exhibits similar enhancements over industrial regions 


\section{GOME Tropospheric $\mathrm{NO}_{2}$ Vertical Column}

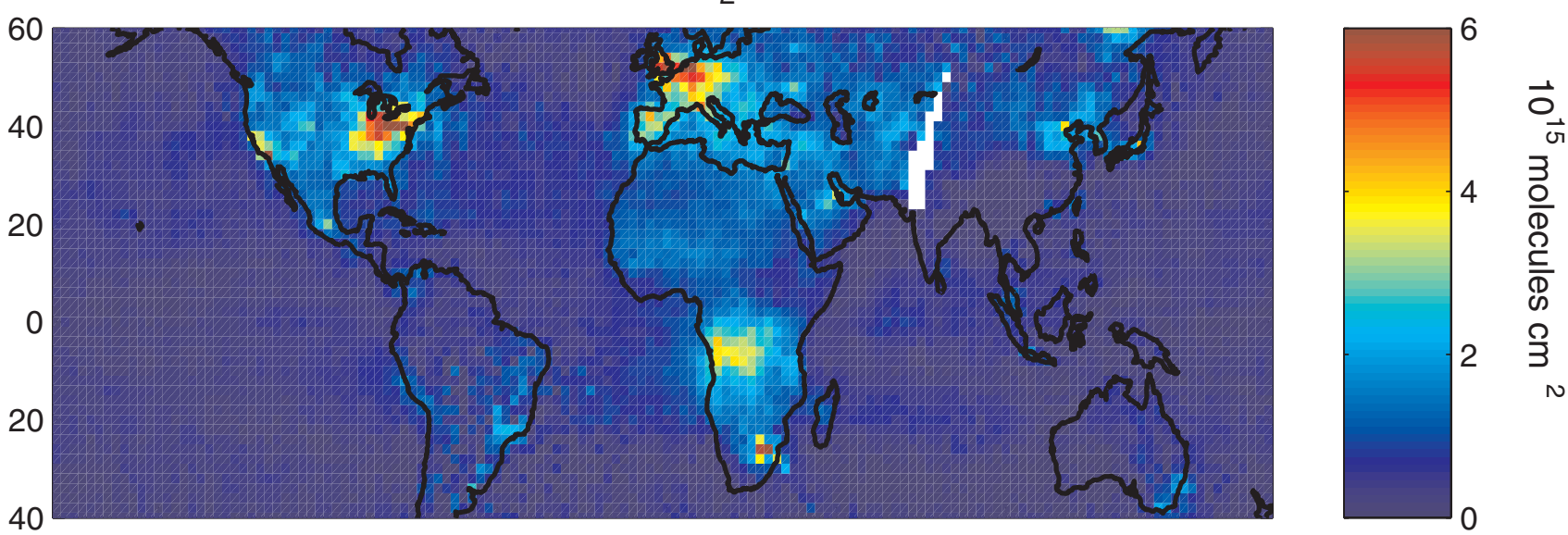

GEOS-CHEM Tropospheric $\mathrm{NO}_{2}$ Column

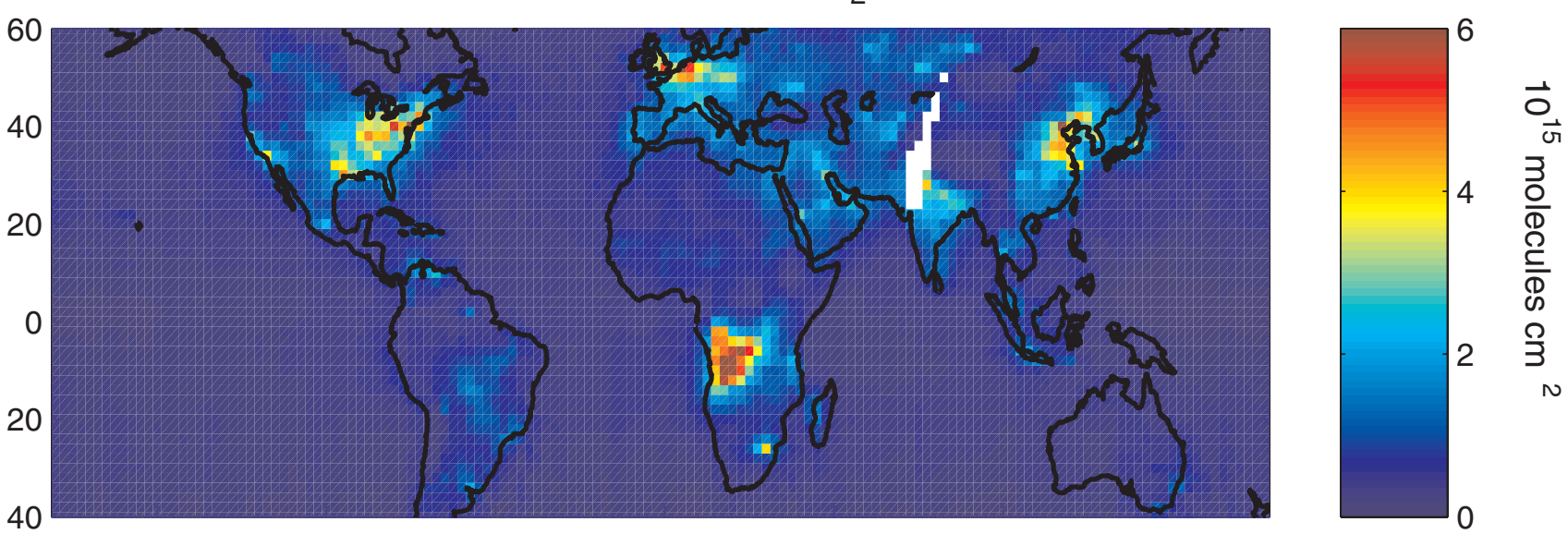

Figure 12. July 1996 mean tropospheric $\mathrm{NO}_{2}$ vertical columns from GOME (top) and the GEOSCHEM model (middle). (bottom) The difference between the two (note change of scale).

of Europe, the eastern United States, eastern Asia, and over the biomass burning region of central Africa, but their $\mathrm{NO}_{2}$ columns over each region are about twice the magnitude of the $\mathrm{NO}_{2}$ columns presented here for July 1996. As dis- cussed in section 3.4, this difference can be explained by their treatment of clouds in the AMF calculation. Another difference is their assumption of zero tropospheric $\mathrm{NO}_{2}$ over oceanic scenes, which we argue leads to significant bias 


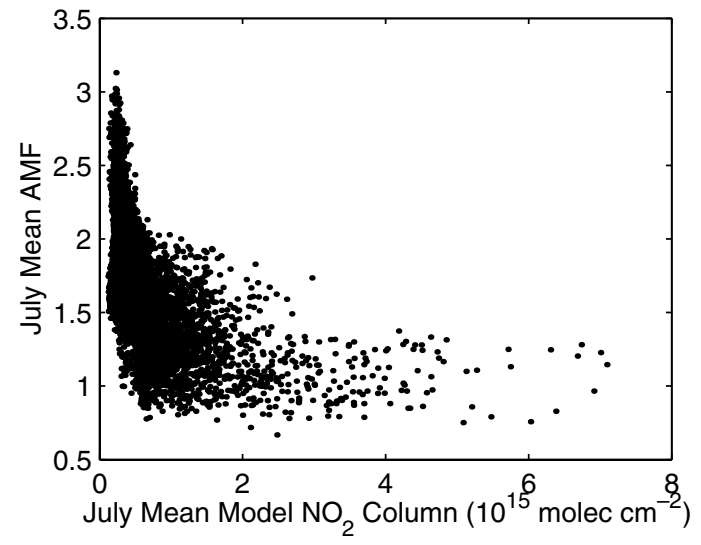

Figure 13. Relationship between the AMF and the modeled $\mathrm{NO}_{2}$ columns for July 1996.

(section 5.1). Comparison between the $\mathrm{NO}_{2}$ columns presented here with those presented by Leue et al. [2001] is more difficult since they only provide yearly mean values and tropospheric $\mathrm{NO}_{2}$ columns in winter are about twice the magnitude of those in summer [Velders et al., 2001]. The spatial structure between the two exhibit some consistency over land.

\section{Error Analysis}

[54] In the previous sections we assessed the errors introduced at different steps of the retrieval. Here we synthesize this information to estimate the total error and identify the dominant contributions. We express the total tropospheric vertical column error $\varepsilon$ as the quadrature sum of (1) the slant column fitting error $\varepsilon_{f}$, (2) the error $\varepsilon_{s}$ incurred in the determination of the nontropospheric slant column, (3) the error $\varepsilon_{b}$ in the bias correction for tropospheric $\mathrm{NO}_{2}$ over the Pacific, (4) the error $\varepsilon_{v}$ from zonal variability in the stratospheric column, (5) the error $\varepsilon_{\sigma}$ due to uncertainty in the $\mathrm{NO}_{2}$ absorption cross section, and (6) the error $\varepsilon_{A}$ in the AMF calculation

$$
\varepsilon=\sqrt{\left(\frac{\varepsilon_{f}}{\mathrm{AMF}}\right)^{2}+\left(\frac{\varepsilon_{s}}{\mathrm{AMF}}\right)^{2}+\left(\frac{\varepsilon_{b}}{\mathrm{AMF}}\right)^{2}+\varepsilon_{\nu}^{2}+\left(\varepsilon_{\sigma} \Omega\right)^{2}+\left(\varepsilon_{A} \Omega\right)^{2}} .
$$

The slant column errors in the first three terms are normalized by the tropospheric AMF and the last two are normalized by the tropospheric vertical column $\Omega$.
[55] Table 3 summarizes the error estimates. The tropospheric AMF is taken here as 1.3 over land and 2.0 over ocean (Figure 4, bottom). The slant column fitting precision $\varepsilon_{f}$ is typically $1.1 \times 10^{15}$ molecules $\mathrm{cm}^{-2}$. Over northern midlatitudes where the minimum number of observations (17) is used to determine the nontropospheric slant columns, the error $\varepsilon_{s}$ is $3 \times 10^{14}$ molecules $\mathrm{cm}^{-2}$. The GEOSCHEM simulation of aircraft observations over the remote Pacific can overestimate $\mathrm{NO}_{2}$ columns by up to a factor of 2 ; at $40^{\circ} \mathrm{N}$ where the bias correction for tropospheric $\mathrm{NO}_{2}$ is largest (Figure 8, bottom), the slant column error $\varepsilon_{b}$ is about $3.5 \times 10^{14}$ molecules $\mathrm{cm}^{-2}$. Figure 10 shows that poleward of $30^{\circ} \varepsilon_{v}$ is about $3 \times 10^{14}$ molecules $\mathrm{cm}^{-2}$ at sunrise and sunset. At the time of the GOME overpass ( 1030 AM), $\varepsilon_{v}$ is about half the sunrise/sunset values, small compared with $\varepsilon_{f}$. The error in the $\mathrm{NO}_{2}$ cross section is $4 \%$ [Burrows et al., 1998], negligible over both land and ocean.

[56] We calculate $\varepsilon_{a}$ separately over ocean and land. Over ocean the tropospheric $\mathrm{NO}_{2}$ column is typically less than 2 $\times 10^{15}$ molecules $\mathrm{cm}^{-2}$. Clouds are the most important contributor to variability in the AMF there, with typically a $30 \%$ effect. Even if a 50\% error exists in GOMECAT cloud data, $\varepsilon_{A} \Omega$ would be $3 \times 10^{14}$ molecules $\mathrm{cm}^{-2}$, small compared to the error from $\varepsilon_{f}$.

[57] Over land the tropospheric $\mathrm{NO}_{2}$ column ranges from $1 \times 10^{15}$ to $6 \times 10^{15}$ molecules $\mathrm{cm}^{-2}$ and the relative error in the AMF is more important. The AMF calculation is most sensitive to surface albedo, the $\mathrm{NO}_{2}$ shape factor, and cloud information. The precision of the surface albedo data is 0.02 [Koelemeijer et al., 2002], yielding a corresponding error $\varepsilon_{a}$ of up to $28 \%$ over the Pennsylvania scene for a typical surface albedo of 0.04 . Surface albedo is particularly important in determining the sensitivity of GOME to boundary layer $\mathrm{NO}_{2}$ over nonfrozen surfaces.

[58] Most $\mathrm{NO}_{2}$ over land is in the boundary layer and the shape of the $\mathrm{NO}_{2}$ profile is largely determined by boundary layer depth. As shown by Fiore et al. [2002], GEOS July mean boundary layer depths used in GEOS-CHEM are consistent with observations over the United States. Temporal variability is more difficult to evaluate given the limited number of observations. Inland observations over the northeastern United States indicate that daily variability in the July boundary layer depth is less than 100 $\mathrm{hPa}$ [Berman et al., 1999]. We calculate the error in the AMF calculation by assuming that the GEOS data have no skill in simulating $\pm 100 \mathrm{hPa}$. For the Pennsylvania case (Figure 2), we find that AMFs calculated for boundary

Table 3. Error in the Retrieval of Tropospheric Vertical $\mathrm{NO}_{2}$ Column From GOME $\left(10^{15}\right.$ molecules $\mathrm{cm}^{-2}$ )

\begin{tabular}{lcc}
\hline & Ocean & Land \\
\hline Fitting, $\varepsilon_{f} / \mathrm{AMF}$ & 0.6 & 0.8 \\
Determination of the nontropospheric column, $\varepsilon_{s} / \mathrm{AMF}$ & 0.1 & 0.2 \\
Pacific bias correction, $\varepsilon_{b} / \mathrm{AMF}$ & 0.2 & 0.3 \\
Assumption of a zonally invariant stratospheric column, $\varepsilon_{v}$ & 0.2 & 0.2 \\
$\mathrm{NO}_{2}$ cross section, $\varepsilon_{\sigma} \Omega$ & 0.04 & $0.04-0.2$ \\
$\mathrm{AMF}$ calculation, $\varepsilon_{A} \Omega$ & 0.3 & $0.5-3.2$ \\
Total error (quadrature sum) & $\mathbf{0 . 7}$ & $\mathbf{1 . 0}-\mathbf{3 . 3}$ \\
\hline
\end{tabular}

The above errors are for each observation. In the unlikely event of truly random errors, the monthly mean error for each $2^{\circ} \times 2.5^{\circ}$ model grid box would be $1 \times 10^{14}$ molecules $\mathrm{cm}^{-2}$ over ocean and $2-7 \times 10^{14}$ molecules cm ${ }^{-2}$ over land. 
layer depths of 700 and $900 \mathrm{hPa}$ differ by $15 \%$ from the value at $800 \mathrm{hPa}$.

[59] Clouds and aerosols are an obvious source of error in the AMF calculation. Of the three cloud parameters used to calculate AMFs in the cloudy scenes (cloud fraction $f$, cloud top pressure, and cloud optical thickness $\tau_{c}$ ) the cloud optical thickness makes the largest contribution to the AMF error. We find that cloud top pressure generally has little effect on the AMF over land since they are nearly always above the boundary layer. Both $f$ and $\tau_{c}$ affect the fraction of $I$ from the cloudy subscene in the AMF calculation (equation (11)), but of the two $\tau_{c}$ is more uncertain. The error in the $\tau_{c}$ measurement increases with decreasing $f$. We make a conservative estimate of the error in the AMF calculation by assuming factors of 10,5 , and 2 errors in $\tau_{c}$ for the Pennsylvania scene for $f$ of $0.1,0.2$, and 0.5 , respectively, yielding corresponding errors of $16 \%, 28 \%$, and $27 \%$. The error in the AMF decreases with decreasing $f$ in spite of the increased error in $\tau_{c}$. In fact the errors on $f$ and $\tau_{c}$ derived by GOMECAT are negatively correlated because of the constraint from observed reflectivity; therefore the combined error in the AMF from $f$ and $\tau_{c}$ is generally less than from $\tau_{c}$ alone. We estimate an additional $10 \%$ error from uncertainties in modeling the cloud radiation transfer characteristics such as the phase function and the representation of multiple clouds as a single cloud. As pointed out earlier, the GOMECAT algorithm effectively treats a thick aerosol layer as a thin cloud. Palmer et al. [2001] found a $30 \%$ decrease of the AMF for a scattering aerosol in the boundary layer with an optical thickness of 1 [Palmer et al., 2001]. Absorbing aerosols would have an opposite effect. Combining all the above effects, an upper bound for the quadrature sum of the error from surface albedo, boundary layer depths, clouds, and aerosols is $53 \%$. The corresponding total error $\varepsilon_{A} \Omega$ ranges from $5 \times 10^{14}$ to $3.2 \times 10^{15}$ molecules $\mathrm{cm}^{-2}$ for a tropospheric $\mathrm{NO}_{2}$ column range of $1 \times 10^{15}$ to $6 \times 10^{15}$ molecules $\mathrm{cm}^{-2}$.

[60] As summarized in Table 3, the total error on the $\mathrm{NO}_{2}$ tropospheric column retrieval is dominated by the fitting precision over ocean and land regions with low $\mathrm{NO}_{2}$ columns. Over major continental source regions, the AMF calculation can be a more important contributor to the total error, due mostly to errors in surface albedo and clouds. On average about 2.5 observations are made in each $2^{\circ} \times 2.5^{\circ}$ grid box for each of the $10 \mathrm{GOME}$ overpasses per month. If the errors were truly random, the monthly mean error for each model grid box would be $1 \times 10^{14}$ molecules $\mathrm{cm}^{-2}$ over ocean and $2-7 \times 10^{14}$ molecules $\mathrm{cm}^{-2}$ over land. In practice, the errors likely include some systematic biases such as from surface albedo and aerosols.

\section{Conclusions and Recommendations for Further Work}

[61] We have presented a retrieval of tropospheric $\mathrm{NO}_{2}$ vertical columns from GOME that improves in several ways over previous retrievals, especially in the AMF formulation used to convert slant columns to vertical columns. For each GOME observation, we calculate an AMF from the relative vertical $\mathrm{NO}_{2}$ distribution (shape factor) determined locally with a 3-D global model of tropospheric chemistry (GEOSCHEM), weighted by altitude-dependent scattering weights computed with a radiative transfer model (LIDORT). The AMF calculation uses local surface albedos determined from GOME near the center of the $\mathrm{NO}_{2}$ fitting window $(440 \mathrm{~nm})$ and near the same wavelength used in the AMF calculation. It accounts for cloud scattering using GOME cloud fraction, cloud top pressure, and cloud optical thickness from a cloud retrieval algorithm (GOMECAT). We find that clouds increase the sensitivity of GOME to tropospheric $\mathrm{NO}_{2}$ columns over ocean by up to $40 \%$, and decrease the sensitivity of GOME to tropospheric $\mathrm{NO}_{2}$ columns over continental source regions by $20-30 \%$. In general GOME is almost twice as sensitive to tropospheric $\mathrm{NO}_{2}$ columns over ocean than over land due to differences in the shape of the $\mathrm{NO}_{2}$ profile.

[62] Several additional algorithm improvements were presented. Slant $\mathrm{NO}_{2}$ columns, which are directly fitted without low-pass filtering or spectral smoothing, are corrected daily for an artificial offset likely induced by spectral structure on the diffuser plate of the GOME instrument. We determine the stratospheric $\mathrm{NO}_{2}$ column and the magnitude of the diffuser plate artifact by using data over the central Pacific Ocean, where tropospheric $\mathrm{NO}_{2}$ is particularly low, and then use the GEOS-CHEM model to account for nonzero tropospheric $\mathrm{NO}_{2}$ over that region. Retrieved columns are available at http://www-as.harvard.edu/chemistry/trop/ satellite/no2.html.

[63] Retrieved tropospheric vertical columns from GOME for July 1996 exhibit a high degree of consistency with simulated columns from GEOS-CHEM. Over the United States, where $\mathrm{NO}_{\mathrm{x}}$ emissions are particularly well known, retrieved columns are $18 \%$ higher than GEOSCHEM and monthly mean values are strongly spatially correlated $(\mathbf{r}=0.78, \mathrm{n}=288, \mathrm{p}<0.005)$. The GOME columns are lower than GEOS-CHEM columns over Houston, the biomass burning region of central Africa, northern India, and eastern Asia; all those have high concentrations of absorbing aerosols that could introduce a bias in the AMF calculation. Retrieved columns over the Transvaal region of South Africa, a major region of electricity generation, are about $50 \%$ higher than GEOS-CHEM values. GOME columns also are higher over the northeastern US and industrial regions of Europe. No enhancements are apparent over aircraft corridors or regions of intense lightning activity, consistent with the strong weighting of the $\mathrm{NO}_{2}$ vertical distribution toward the lower troposphere.

[64] This study confirms that GOME observations can be used to map surface emissions of $\mathrm{NO}_{2}$. Lightning activity is much more difficult to detect due to large relative errors over oceans, the weak sensitivity of $\mathrm{NO}_{2}$ columns to upper tropospheric $\mathrm{NO}_{\mathrm{x}}$, and the large GOME spatial resolution. The error in the retrieval of tropospheric $\mathrm{NO}_{2}$ is dominated by the spectral fitting precision over the oceans and over continental regions with low $\mathrm{NO}_{2}$ columns. Over regions of enhanced $\mathrm{NO}_{2}$ columns $\left(>2 \times 10^{15}\right.$ molecules $\left.\mathrm{cm}^{-2}\right)$ the AMF calculation becomes a more important contributor to the total error mostly because of clouds, aerosols, and surface albedo.

[65] Extension of this analysis to a full year should examine seasonal changes in zonal variability of strato- 
spheric $\mathrm{NO}_{2}$ columns and daily varying surface albedos from snow cover. Accounting for aerosols should improve the accuracy of the AMF calculation since $\mathrm{NO}_{2}$ emissions are frequently associated with aerosols. Independent characterization of temporal variation in the diffuser plate artifact may enable more accurate removal of the stratospheric vertical columns. Future satellite instruments with smaller fields of view to reduce cloud contamination, such as SCIAMACHY on board ENVISAT and OMI on board AURA, should further improve the potential to retrieve tropospheric $\mathrm{NO}_{2}$ columns from solar backscatter measurements.

[66] Acknowledgments. We gratefully acknowledge helpful discussions about HALOE and stratospheric variability with Anne Douglass, Dylan Jones, Ross Salawitch, and Hans Schneider. We thank Folkert Boersma, Ellen Brinksma, John Burrows, Ulrich Platt, Andreas Richter, Piet Stammes, and Pepijn Veefkind for comments. This work was supported by the NASA Atmospheric Chemistry Modeling and Analysis Program. Randall V. Martin was supported by a National Defense and Engineering Graduate Fellowship.

\section{References}

Bachmeier, A. S., and H. E. Fuelberg, A meteorological overview of the TRACE A period, J. Geophys. Res., 101, 23,881-23,888, 1996.

Benkovitz, C. M., M. T. Schultz, J. Pacyna, L. Tarrason, J. Dignon, E. C. Voldner, P. A. Spiro, J. A. Logan, and T. E. Graedel, Global gridded inventories for anthropogenic emissions of sulfur and nitrogen, J. Geophys. Res., 101, 29,239-29,253, 1996.

Berman, S., J.-Y. Ku, and S. T. Rao, Spatial and temporal variation in the mixing depth over the northeastern United States during the summer of 1995, J. Appl. Meteorol., 38, 1661-1673, 1999.

Bey, I., D. J. Jacob, R. M. Yantosca, J. A. Logan, B. D. Field, A. M. Fiore, Q. Li, H. Y. Liu, L. J. Mickley, and M. G. Schultz, Global modeling of tropospheric chemistry with assimilated meteorology: Model description and evaluation, J. Geophys. Res., 106, 23,073-23,096, 2001a.

Bey, I., D. J. Jacob, J. A. Logan, and R. M. Yantosca, Asian chemical outflow to the Pacific: Origins, pathways and budgets, J. Geophys. Res., 106, 23,097-23,114, 2001b.

Bradshaw, J., et al., Photofragmentation two-photon laser-induced fluorescence detection of $\mathrm{NO}_{2}$ and $\mathrm{NO}$ : Comparison of measurements with model results based on airborne observations during PEM-Tropics A, Geophys. Res. Lett., 26, 471-474, 1999.

Burrows, J. P., et al., Global Ozone Monitoring Experiment Interim Science Report, ESA Publ. Div., ESTEC, Noordwijk, The Netherlands, 1993.

Burrows, J. P., A. Dehn, B. Deters, S. Himmelmann, A. Richter, S. Voigt, and J. Orphal, Atmospheric remote-sensing reference data from GOME, part 1, Temperature-dependent absorption cross-sections of $\mathrm{NO}_{2}$ in the 231-794 nm range, J. Quant. Spectrosc. Radiat. Transfer, 60, $1025-$ 1031,1998 .

Burrows, J. P., et al., The Global Ozone Monitoring Experiment (GOME): Mission concept and first scientific results, J. Atmos. Sci., 56, 151-175, 1999a.

Burrows, J. P., A. Richter, A. Dehn, B. Deters, S. Himmelmann, S. Voigt, and J. Orphal, Atmospheric remote-sensing reference data from GOME, 2, Temperature-dependent absorption cross sections of $\mathrm{O}_{3}$ in the $231-$ 794 nm range, J. Quant. Spectrosc. Radiat. Transfer, 61, 509-517, $1999 b$.

Caspar, C., and K. Chance, GOME wavelength calibration using solar and atmospheric spectra, in Proceedings of the Third ERS Symposium on Space at the Service of our Environment, edited by T.-D. Guyenne and D. Danesy, Eur. Space Agency, Publication SP-414, 1997.

Chance, K., Analysis of BrO measurements from the Global Ozone Monitoring Experiment, Geophys. Res. Lett., 25, 3335-3338, 1998.

Chance, K. V., and R. J. D. Spurr, Ring effect studies: Rayleigh scattering, including molecular parameters for rotational Raman scattering, and the Fraunhofer spectrum, Appl. Opt., 36, 5224-5230, 1997.

Chance, K., P. Palmer, R. J. D. Spurr, R. V. Martin, T. P. Kurosu, and D. J. Jacob, Satellite observations of formaldehyde over North America from GOME, Geophys. Res. Lett., 27, 3461-3464, 2000.

Chandrasekhar, S., Radiative Transfer, Dover, Mineola, N. Y., 1960.

Corbett, J. J., P. S. Fischbeck, and S. N. Pandis, Global nitrogen and sulfur inventories for ocean-going ships, J. Geophys. Res., 104, 3457-3470, 1999.

Davis, D. D., G. Grodzinsky, P. Kasibhatla, J. Crawford, G. Chen, S. Liu,
A. Bandy, D. Thornton, H. Guan, and S. Sandholm, Impact of ship emissions on marine boundary layer $\mathrm{NO}_{\mathrm{x}}$ and $\mathrm{SO}_{2}$ distributions over the Pacific Basin, Geophys. Res. Lett., 28, 235-238, 2001.

De Haan, J. F., P. B. Bosma, and J. W. Hovenier, The adding method for multiple scattering calculations of polarized light, Astron. Astrophys., 183, 371-391, 1987.

Duncan, B. N., R. V. Martin, A. C. Staudt, R. Yevich, and J. A. Logan, Interannual and seasonal variability of biomass burning emissions constrained by satellite observations, J. Geophys. Res., doi:10.1029/ 2002JD002378, in press, 2002.

Emmons, L. K., et al., Climatologies of $\mathrm{NO}_{\mathrm{x}}$ and $\mathrm{NO}_{\mathrm{y}}$ : A comparison of data and models, Atmos. Environ., 31, 1851-1904, 1997.

EPA, National Air Pollutant Emission Trends, 1990-1996, US EPA, Research Triangle Park, 1997.

ESA, in The GOME Users Manual, edited by F. Bednarz, ESA Publ. Div., ESTEC, Noordwijk, The Netherlands, 1995.

Fiore, A. M., D. J. Jacob, I. Bey, R. M. Yantosca, B. D. Field, and J. G. Wilkinson, Background ozone over the United States in summer: Origin and contribution to pollution episodes, J. Geophys. Res., 107, 4279, doi:10.1029/2001JD000982, 2002.

Fishman, J., V. G. Brackett, E. V. Browell, and W. B. Grant, Tropospheric ozone derived from TOMS/SBUV measurements during TRACE A, J. Geophys. Res., 101, 24,069-24,082, 1996a.

Fishman, J., J. M. Hoell, R. D. Bendura, R. J. McNeil, and V. W. J. H. Kirchhoff, NASA GTE TRACE A experiment (September-October 1992): Overview, J. Geophys. Res., 101, 23,865-23,879, 1996 b.

Gordley, L. L., et al., Validation of nitric oxide and nitrogen dioxide measurements made by the Halogen Occultation Experiment for UARS platform, J. Geophys. Res., 101, 10,241-10,266, 1996.

Gordon, H. R., Contribution of Raman scattering to water-leaving radiance: A reexamination, Appl. Opt., 38, 3166-3174, 1999.

Hansen, J., G. Russell, D. Rind, P. Stone, A. Lacis, S. Lebedeff, R. Ruedy, and L. Travis, Efficient three-dimensional global models for climate studies: Models I and II, Mon. Weather Rev., 111, 609-662, 1983.

Herman, J. R., P. K. Bhartia, O. Torres, C. Hsu, C. Seftor, and E. Celarier, Global distribution of UV-absorbing aerosols from Nimbus 7-TOMS data, J. Geophys. Res., 102, 16,911-16,922, 1997.

Horowitz, L. W., J. Y. Liang, G. M. Gardner, and D. J. Jacob, Export of reactive nitrogen from North America during summertime, J. Geophys. Res., 103, 13,451-13,476, 1998.

Hübler, G., et al., An overview of the airborne activities during the Southern Oxidants Study (SOS) 1995 Nashville/Middle Tennessee Ozone Study, J. Geophys. Res., 103, 22,245-22,259, 1998.

Jacob, D. J., et al., Origin of ozone and $\mathrm{NO}_{\mathrm{x}}$ in the tropical troposphere: A photochemical analysis of aircraft observations over the South Atlantic basin, J. Geophys. Res., 101, 24,235-24,250, 1996.

Jacobson, M. Z., and R. P. Turco, SMVGEAR: A sparse-matrix, vectorized Gear code for atmospheric models, Atmos. Environ., 28, 273-284, 1994.

Kasibhatla, P. S., H. Levy, W. J. Moxim, and W. L. Chameides, The relative importance of stratospheric photochemical production on tropospheric NO levels: A model study, J. Geophys. Res., 96, 18,631-18,646, 1991.

Kasibhatla, P., et al., Do emissions from ships have a significant impact on concentrations of nitrogen oxides in the marine boundary layer?, Geophys. Res. Lett., 27, 2229-2232, 2000.

Kattawar, G. W., and X. Xu, Filling in of Fraunhofer lines in the ocean by Raman scattering, Appl. Opt., 31, 6491-6500, 1992.

Koelemeijer, R. B. A., and P. Stammes, Effects of clouds on ozone column retrieval from GOME UV measurements, J. Geophys. Res., 104, 82818294, 1999.

Koelemeijer, R. B. A., J. F. de Haan, and P. Stammes, A database of spectral surface reflectivity of the Earth in the range $335-772 \mathrm{~nm}$ derived from 5.5 years of GOME observations, J. Geophys. Res., doi:10.1029/ 2002JD002429, in press, 2002.

Kurosu, T. P., K. Chance, and R. J. D. Spurr, CRAG: Cloud Retrieval Algorithm for ESA's Global Ozone Monitoring Experiment, in European Symposium on Atmospheric Measurements from Space, 1999.

Lee, D. S., I. Köhler, E. Grobler, F. Rohrer, R. Sausen, L. Gallardo-Klenner, J. H. J. Olivier, F. J. Dentener, and A. F. Bouwman, Estimations of global $\mathrm{NO}_{\mathrm{x}}$ emissions and their uncertainties, Atmos. Environ., 31, 1735-1749, 1997.

Leue, C., M. Wenig, T. Wagner, O. Klimm, U. Platt, and B. Jahne, Quantitative analysis of $\mathrm{NO}_{\mathrm{x}}$ emissions from GOME satellite image sequences, J. Geophys. Res., 106, 5493-5505, 2001.

Liang, J., L. W. Horowitz, D. J. Jacob, A. M. Fiore, J. A. Logan, G. M. Gardner, and J. W. Munger, Seasonal budgets of reactive nitrogen species and ozone over the United States and export fluxes to the global atmosphere, J. Geophys. Res., 103, 13,435-13,450, 1998.

Martin, R. V., et al., Interpretation of TOMS observations of tropical tropospheric ozone with a global model and in situ observations, J. Geophys. Res., 107(D18), 4351, doi:10.1029/2001JD001480, 2002. 
McPeters, R. D., et al., Earth Probe Total Ozone Mapping Spectrometer (TOMS) Data Products User's Guide, 1998.

Munger, J. W., S.-M. Fan, P. S. Bakwin, M. L. Goulden, A. H. Goldstein A. S. Colman, and S. C. Wofsy, Regional budgets for nitrogen oxides from continental sources: Variations of rates for oxidation and deposition with season and distance from source regions, J. Geophys. Res., 103, 8355-8368, 1998.

Murphy, D., D. Fahey, M. Proffitt, S. Liu, C. Eubank, S. Kawa, and K. Kelly, Reactive odd nitrogen and its correlation with ozone in the lower stratosphere and upper troposphere, J. Geophys. Res., 98, 8751-8773, 1993.

National Research Council, Global Air Quality: An Imperative for LongTerm Observational Strategies, 41 pp., Natl. Acad. Press, 2001.

Palmer, P. I., D. J. Jacob, K. Chance, R. V. Martin, R. J. D. Spurr, T. P. Kurosu, I. Bey, R. Yantosca, A. Fiore, and Q. Li, Air mass factor formulation for spectroscopic measurements from satellites: Application to formaldehyde retrievals from the Global Ozone Monitoring Experiment, J. Geophys. Res., 106, 14,539-14,550, 2001.

Penner, J. E., C. S. Athertson, J. Dignon, S. J. Ghan, J. J. Walton, and S. Hameed, Tropospheric nitrogen: A three-dimensional study of sources, distributions, and deposition, J. Geophys. Res., 96, 959-990, 1991.

Pickering, K. E., et al., Convective transport of biomass burning emissions over Brazil during Trace A, J. Geophys. Res., 101, 23,993-24,012, 1996.

Pickering, K. E., Y. S. Wang, W. K. Tao, C. Price, and J. F. Muller, Vertical distributions of lightning $\mathrm{NO}_{\mathrm{x}}$ for use in regional and global chemical transport models, J. Geophys. Res., 103, 31,203-31,216, 1998.

Platt, U., Differential optical absorption spectroscopy (DOAS), in Air Monitoring by Spectroscopic Techniques, edited by M. Siegrist, John Wiley, New York, 1994.

Press, W. H., B. P. Flannery, S. A. Teukolsky, and W. T. Vetterling, Numerical Recipes in Fortran, 963 pp., Cambridge Univ. Press, New York, 1986

Price, C., and D. Rind, A simple lightning parameterization for calculating global lightning distributions, J. Geophys. Res., 97, 9919-9933, 1992.

Raper, J. L., M. M. Kleb, D. J. Jacob, D. D. Davis, R. E. Newell, H. E. Fuelberg, R. J. Bendura, J. M. Hoell, and R. J. McNeal, Pacific Exploratory Mission in the tropical Pacific: PEM-Tropics B, March-April 1999, J. Geophys. Res., 106, 32,401-32,425, 2002.

Richter, A., and J. P. Burrows, Tropospheric $\mathrm{NO}_{2}$ from GOME measurements, Adv. Space Res., in press, 2002.

Richter, A., F. Wittrock, A. Ladstätter-Weibenmayaer, and J. P. Burrows, GOME measurements of stratospheric and tropospheric BrO, Adv. Space Res., in press, 2002

Rothman, L. S., et al., The HITRAN molecular spectroscopic database and HAWKS (HITRAN atmospheric workstation): 1996 edition, J. Quant Spectrosc. Radiat. Transfer, 60, 665-710, 1998.

Russell, J. M., L. L. Gordley, J. H. Park, S. R. Drayson, W. D. Hesketh, R J. Cicerone, A. F. Tuck, J. E. Frederick, J. E. Harries, and P. J. Crutzen, The HALogen Occultation Experiment, J. Geophys. Res., 98, 10,77710,797, 1993

Ryerson, T. B., L. G. Huey, K. Knapp, J. A. Neuman, D. D. Parrish, D. T. Sueper, and F. C. Fehsenfeld, Design and initial characterization of an inlet for gas-phase $\mathrm{NO}_{\mathrm{y}}$ measurements from aircraft, J. Geophys. Res., 104, 5483-5492, 1999.

Scholes, R. J., J. Kendall, and C. O. Justice, The quantity of biomass burned in southern Africa, J. Geophys. Res., 101, 23,667-23,676, 1996.
Schubert, S. D., R. B. Rood, and J. Pfaendtner, An assimilated data set for Earth Science applications, Bull. Am. Meteorol. Soc., 74, 2331-2342, 1993.

Spurr, R. J. D., T. P. Kurosu, and K. V. Chance, A linearized discrete ordinate radiative transfer model for atmospheric remote sensing retrieval, J. Quant. Spectrosc. Radiat. Transfer, 68, 689-735, 2001.

Stammes, P. Spectral radiance modelling in the UV-visible range, in Proceedings of the International Radiation Symposium, 2000: Current Problems in Atmospheric Radiation, edited by W. L. Smith and Y. M. Timofeyev, A. Deepak, Hampton, Va., 2000.

Thakur, A. N., H. B. Singh, P. Mariani, Y. Chen, Y. Wang, D. J. Jacob, G. Brasseur, J.-F. Müller, and M. Lawrence, Distribution of reactive nitrogen species in the remote free troposphere: Data and model comparisons, Atmos. Environ., 33, 1403-1422, 1999

Thomas, W., E. Hegels, S. Slijkhuis, R. Spurr, and K. Chance, Detection of biomass burning combustion products in Southeast Asia from backscatter data taken by the GOME spectrometer, Geophys. Res. Lett., 25, $1317-$ 1320, 1998.

Thompson, A. M., D. P. McNamara, K. E. Pickering, and R. D. McPeters, Effect of marine stratocumulus on TOMS Ozone, J. Geophys. Res., 98, 23,051-23,058, 1993.

US Standard Atmosphere Supplements, 1976, US Govt. Print. Off., Washington, D. C., 1976.

Velders, G. J. M., C. Granier, R. W. Portmann, K. Pfeilsticker, M. Wenig, T. Wagner, U. Platt, A. Richter, and J. P. Burrows, Global tropospheric $\mathrm{NO}_{2}$ column distributions: Comparing 3-D model calculations with GOME measurements, J. Geophys. Res., 106, 12,643-12,660, 2001.

Walrafen, G. E., Raman spectral studies of the effects of temperature on water structure, J. Chem. Phys., 47, 114-126, 1967.

Wang, Y., D. J. Jacob, and J. A. Logan, Global simulation of tropospheric $\mathrm{O}_{3}-\mathrm{NO}_{\mathrm{x}}$-hydrocarbon chemistry, 1, Model formulation, J. Geophys. Res., 103, 10,713-10,726, 1998.

Wennberg, P. O., et al., Removal of stratospheric $\mathrm{O}_{3}$ by radicals: In situ measurements of $\mathrm{OH}, \mathrm{HO}_{2}, \mathrm{NO}, \mathrm{NO}_{2}, \mathrm{ClO}$, and $\mathrm{BrO}$, Science, 266, $398-$ 404, 1994

Wild, O., X. Zhu, and M. J. Prather, Fast-J: Accurate simulation of in- and below-cloud photolysis in tropospheric chemistry models, J. Atmos. Chem., 37, 245-282, 2000

Yienger, J. J., and H. Levy, Empirical model of global soil-biogenic $\mathrm{NO}_{\mathrm{x}}$ emissions, J. Geophys. Res., 100, 11,447-11,464, 1995.

I. Bey, A. M. Fiore, D. J. Jacob, Q. Li, R. V. Martin, P. I. Palmer, and R. M. Yantosca, Division of Engineering and Applied Sciences and Department of Earth and Planetary Sciences, Harvard University, G3D Pierce Hall, 29 Oxford Street, Cambridge, MA 02138, USA. (rvmartin@ fas.harvard.edu)

K. Chance, T. P. Kurosu, and R. J. D. Spurr, Harvard-Smithsonian Center for Astrophysics, Cambridge, MA 02138, USA

E. Bucsela and J. F. Gleason, NASA Goddard Space Flight Center, Greenbelt, MD 20771, USA.

R. B. A. Koelemeijer, Space Research Organization Netherlands, Sarbonnelaan 2, 3584 Utrecht, Netherlands. 